UNIVERSIDADE DE SÃO PAULO

INSTITUTO DE RELAÇÕES INTERNACIONAIS

PROGRAMA DE PÓS-GRADUAÇÃO EM RELAÇÕES INTERNACIONAIS

INGRID TORQUATO OLIVEIRA

AS INSTITUIÇÕES DE ENSINO SUPERIOR E SUA PARTICIPAÇÃO NO SISTEMA NACIONAL DE INOVAÇÃO DA CHINA

São Paulo

2019 
INGRID TORQUATO OLIVEIRA

\section{AS INSTITUIÇÕES DE ENSINO SUPERIOR E SUA PARTICIPAÇÃO NO SISTEMA NACIONAL DE INOVAÇÃO DA CHINA}

Texto Dissertação apresentada ao Programa de Pós Graduação em Relações Internacionais do Instituto de Relações Internacionais da Universidade de São Paulo, para a obtenção do título de Mestre em Relações Internacionais.

Orientadora: Profa. Dra. Natália Dus Poiatti.

São Paulo 
Autorizo a reprodução e divulgação total ou parcial deste trabalho, por qualquer meio convencional ou eletrônico, para fins de estudo e pesquisa, desde que citada a fonte.

\section{Catalogação na publicação \\ Seção Técnica de Biblioteca \\ Instituto de Relações Internacionais da Universidade de São Paulo}

Oliveira, Ingrid Torquato

As instituições de ensino superior e sua participação no sistema nacional de inovação da China / Ingrid Torquato Oliveira ; orientadora: Natália Dus Poiatti. São Paulo, 2019.

$46 \mathrm{p}$.

Dissertação (Mestrado) - Instituto de Relações Internacionais. Universidade de São Paulo, São Paulo, 2020.

1. República Popular da China 2. Inovação 3. Sistema Nacional de Inovação 4. Instituições de Ensino Superior 5. Universidades I. Poiatti, Natália Dus, orient. II. Título.

$\mathrm{CDD}-379.51$ 


\section{FOLHA DE AVALIAÇÃO}

Autor: OLIVEIRA, Ingrid Torquato.

Título: As instituições de ensino superior e sua participação no sistema nacional de inovação da china

Relatório de Exame Final apresentado ao Instituto de Relações Internacionais da Universidade de São Paulo, como requisito para obtenção do título de mestre em Ciências.

Data:

Banca Examinadora

Prof. Dr.:

Instituição: Julgamento:

Prof. Dr.:

Instituição: Julgamento:

Prof. Dr.:

Instituição: Julgamento: 
Autor: OLIVEIRA, Ingrid Torquato. As instituições de ensino superior e sua participação no sistema nacional de inovação da China (48 páginas). Texto de Dissertação final (Mestrado em Ciências) - Instituto de Relações Internacionais, Universidade de São Paulo, São Paulo, 2019.

\section{RESUMO}

Desde 2006 o Partido Comunista da China tem divulgado nos seus planejamentos e diretrizes oficiais o papel da inovação como motor de seu desenvolvimento econômico para os próximos anos. É registrada a ênfase que será dada ao papel da inovação e à Ciência \& Tecnologia na construção de uma sociedade próspera, o chamado "Sonho Chinês". Nessa nova fase, o sistema nacional de inovação está sendo alterado para aprimorar as relações entre seus diversos atores como as instituições de ensino superior, a fim de contribuir para a difusão de inovações e consequentemente ao desenvolvimento do país. Desse modo, apresenta-se como proposta de pesquisa compreender como a participação das instituições de ensino superior (IES) ocorre dentro do sistema nacional de inovação da China, com foco no período de 2006 até 2017 e por províncias. Através da utilização de uma metodologia embasada em análise multivariada de dados amparada pelo estudo do caso chinês e partindo da revisão de literatura sobre o objeto de pesquisa, os objetivos são: compreender as interações entre as IES e outros atores e instituições do sistema nacional de inovação da China; verificar em que medida as IES contribuem para os processos de inovação do país a partir de dados quantitativos de variáveis que mensuram inovação e características das IES.

Palavras-chave: República Popular da China; Inovação; Sistema Nacional de Inovação; Instituições de Ensino Superior; Universidades 


\begin{abstract}
Since 2006, the Communist Party of China has publicized in its official plans and guidelines the role of innovation as the engine of its economic development for years to come. Emphasis will be placed on the role of innovation and Science \& Technology in building a prosperous society, the so-called "Chinese Dream". In this new phase, the national innovation system is being changed to improve the relationships between its various actors such as higher education institutions, in order to contribute to the diffusion of innovations and consequently to the country's development. Thus, it is proposed as a research proposal to understand how the participation of higher education institutions (HEIs) occurs within China's national innovation system, focusing on the period from 2006 to 2017 and by provinces. Through the use of a methodology based on multivariate data analysis supported by the Chinese case study and starting from the literature review about the research object, the objectives are: to understand the interactions between the HEI and other actors and institutions of the national innovation system. from China; To verify the extent to which HEIs contribute to the innovation processes of the country from quantitative data of variables that measure innovation and characteristics of HEIs.
\end{abstract}

Keywords: People's Republic of China; Innovation; National System of Innovation; Higher education institutions; Universities 


\section{SUMÁRIO}

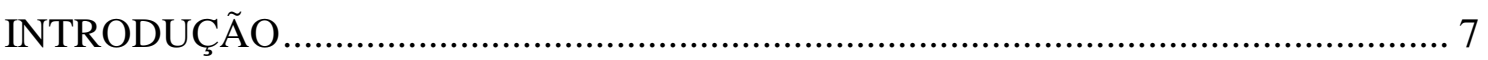

1. INOVAÇÃO, SISTEMAS NACIONAIS DE INOVAÇÃO E INSTITUIÇÕES DE

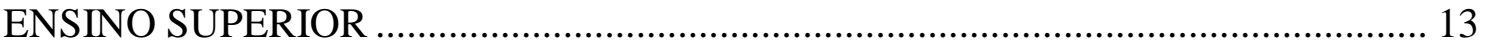

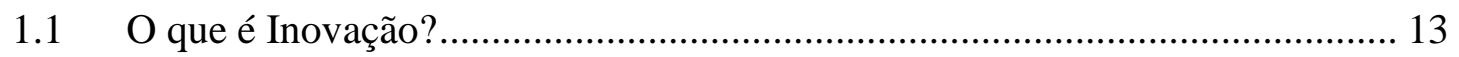

1.2 Estudos sobre Inovação e a abordagem sistêmica .......................................... 16

1.3 Instituições de Ensino Superior como atores de Inovação................................ 20

2. O SISTEMA NACIONAL DE INOVAÇÃO DA CHINA E AS

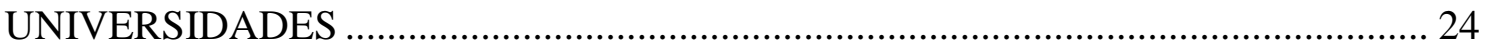

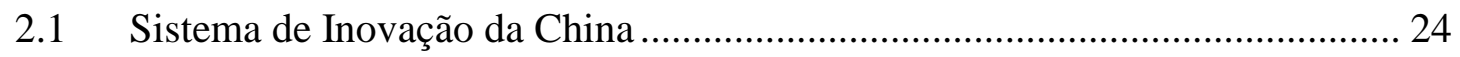

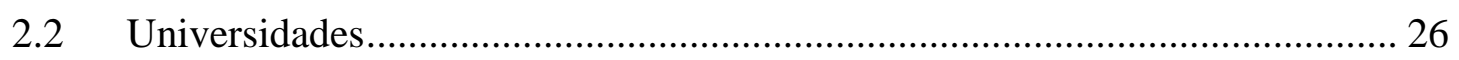

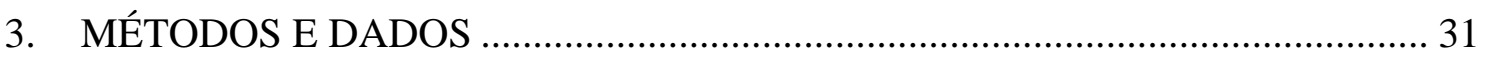

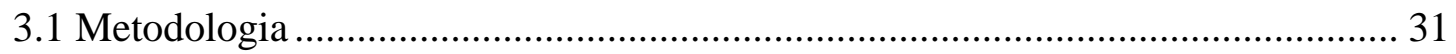

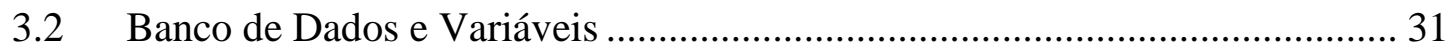

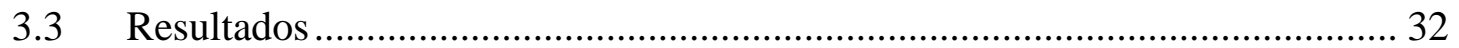

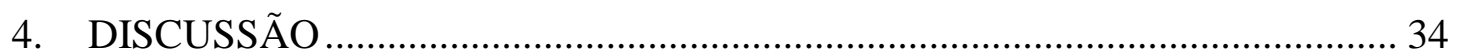

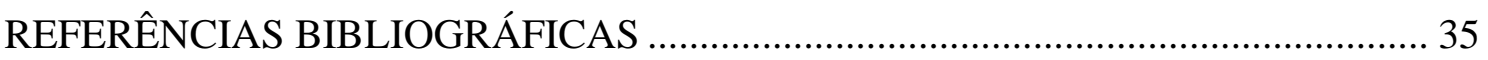

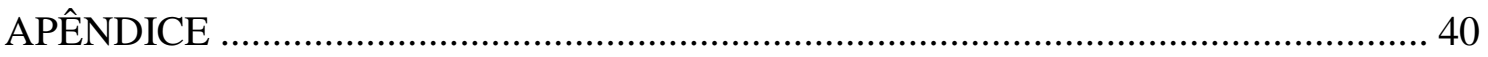




\section{INTRODUÇÃO}

Em um contexto global contemporâneo da chamada Economia do Conhecimento ${ }^{1}$, onde o conhecimento é tido como principal fator de crescimento econômico, a ideia de que diferenças no desenvolvimento dos países se dão pelas diferentes capacidades tecnológicas passa a ser amplamente aceita (LLERENA; MATT, 2005; FAGERBERG; SRHOLEC, 2008). Alcançar os patamares tecnológicos (catch up) dos países que estão dominando e criando novas tecnologias, entretanto, não seria parte de um processo automático, dependendo de políticas específicas voltadas à pauta, de acordo com as características econômicas dos países (FAGERBERG; SRHOLEC, 2008).

Nesse contexto, há de se considerar, também, a profunda mudança no paradigma produtivo e industrial que acompanha a chamada Quarta Revolução Industrial (QRI), pressupondo uma maior interação entre aspectos físicos e digitais no processo de produção, ampliando fortemente a necessidade de bens de capital que sustentariam a automação acelerada de processos produtivos (SCHWAB, 2016).

Exemplos de países que tiveram sucesso nesse processo de catch-up, como o Japão e a Coreia, estiveram longe da passividade de exclusivamente adotar as tecnologias de países mais desenvolvidos, na medida em que adotaram estratégias de desenvolvimento ativas, que contradizem a abordagem do chamado Consenso de Washington ${ }^{2}$. Assim, como Ha-Joon Chang (2002) tratou na sua obra "Chutando a Escada".

A China é tida atualmente como um exemplo de país que tem adotado políticas distintas do Consenso de Washington e que vêm surtindo resultado. De uma economia frágil nos fins da década de 1970, o país ultrapassou as maiores economias uma a uma nas últimas décadas, até conquistar o lugar de segunda maior economia do mundo em 2010 (a partir de dos valores do PIB), atrás apenas dos Estados Unidos (ZHA; HAYHOE, 2015).

\footnotetext{
${ }^{1}$ A Economia do Conhecimento é definida pela OCDE (1997) como "as tendências em economias avançadas no sentido de maior dependência do conhecimento, informação e autos níveis de especialização, e a necessidade de pronto acesso a esses fatores pelos setores privado e público" (OCDE, 1997, p, 35).

${ }^{2}$ O termo ficou popular no final da década de 1980, a partir de um discurso do economista John Williamson, para designar uma série de "conselhos" políticos a fim de ajudar na recuperação econômica da América Latina, que enfatizam as políticas de livre mercado, políticas macroeconômicas restritivas, liberalização do comércio internacional e a privatização, por exemplo.
} 
Entre as décadas de 1980 e 2010 a China apresentou um crescimento econômico médio anual de aproximadamente 10\%. Desde a política de Reforma e Abertura, implementada pelo líder político Deng Xiaoping (1978-1992), ao mesmo tempo que mecanismos de mercado foram introduzidos na economia socialista chinesa, passando a denominar a economia socialista de mercado, isto é, seguindo uma estratégia de liberalização sob controle do Estado (PIRES, 2010) ${ }^{3}$.

A capacidade do país de combinar elementos como a abertura ao investimento estrangeiro e comércio exterior (ortodoxos), com elementos singulares (heterodoxos) de sua experiência única (como sua história milenar, o poder político centralizado do Partido Comunista Chinês) é tida como um dos elementos que propiciaram o sucesso na trajetória da economia chinesa (PAULINO, 2010; PIRES, 2010).

Em geral, os traços da experiência chinesa divergem do Consenso de Washington e caracterizam-se como o que foi denominado por Ramo (2004) como "Consenso de Pequim", ou seja, um conjunto de políticas sociais e econômicas que foram coordenadas pelo Estado chinês. As características principais que o autor chamou de teoremas foram: 1) o Estado apoiando políticas de inovação a fim de dominar o progresso científico e criar sua tecnologia, revelando o papel e valor da inovação para criação de tecnologia própria, deste modo, criando soluções mais rápidas do que os problemas que o crescimento traz; 2) um modelo de desenvolvimento onde sustentabilidade e equidade tornam-se prioridades para controlar a instabilidade e disparidades sociais, isto é, o Estado coordenando a sociedade através de políticas públicas (regulação da migração interna, política do filho único, etc.); 3) uma teoria de autodeterminação para influenciar e despertar na sociedade forças para se mover com suas próprias pernas (RAMO, 2004; PIRES, 2010).

O país, entretanto, se encontra em um período crítico de transição econômica e ajustes estruturais que traz consigo desafios e oportunidades (CHI, 2015). Um dos processos utilizados pelo Partido Comunista Chinês é o planejamento por meio de Planos Quinquenais e outros planos governamentais específicos, que servem para

\footnotetext{
${ }^{3}$ Como não há na literatura ocidental uma definição clara e consensual do que seria o socialismo de mercado chinês, utilizamos a definição encontrada na Constituição chinesa: Artigo 11: Os setores nãopúblicos da economia, como os individuais e privados, operando dentro dos limites prescritos por lei, constituem um importante componente da economia socialista de mercado. O Estado protege os direitos legais e interesses dos desses setores da economia. O Estado encoraja, suporta e guia o desenvolvimento dos setores não-públicos da economia e, de acordo com a lei, os supervisiona e controla. Artigo 15: O Estado pratica uma economia socialista de mercado. O Estado fortalece a legislação econômica, melhora a macro regulação e controle. O Estado proíbe, de acordo com a lei, qualquer organização ou indivíduo de perturbar a ordem socioeconômica (Tradução da autora, NPC, 2004).
} 
controlar e coordenar suas políticas econômicas e sociais, identificando as maiores necessidades, especificidades, potenciais e possibilidades, e tornando públicos seus interesses, objetivos e metas.

No final de 2015 foi publicado pelo Congresso Nacional da China o $13^{\circ}$ Plano Quinquenal, que abrange o quadro político, as prioridades e os objetivos econômicos e sociais para o período entre 2016 e 2020, incluindo uma taxa de crescimento acima de $6,5 \%$ ao ano. Atingir essas metas será crucial para realizar o maior objetivo do plano e do atual governo chinês que é de construir uma "sociedade moderadamente próspera em todos os aspectos" até 2020 (NPC, 2016). ${ }^{4}$ O foco do Plano para se atingir os objetivos econômicos é o uso da inovação como o motor da nova fase de desenvolvimento chinês. ${ }^{5}$

Também em 2015, foi divulgado pelo governo chinês o documento Made in China 2025, reiterando o discurso do $13^{\circ}$ Plano Quinquenal de tornar a inovação a principal fonte de desenvolvimento econômico através de uma produção industrial inovadora, adaptação das instituições de inovação, e promoção de uma produção inovadora trans-industrial e interdisciplinar.

Em 2006, o Ministério da Ciência e Tecnologia (Ministry of Science and Technology-MOST) publicou o Plano Nacional de Médio-Longo Prazo para Desenvolvimento da Ciência e Tecnologia (2006-2020), contendo os objetivos de melhorar a capacidade inovadora do país, isto é, aprimorar o nível de C\&T para promover o desenvolvimento econômico e social do país para manter a segurança nacional, e se tornar um país inovador até 2020 (MOST, 2006).

Já o Plano Nacional de Médio-Longo Prazo para Reforma e Desenvolvimento da Educação (2010-2020) contém medidas que diz respeito principalmente a reforma do sistema educacional chinês, na medida em que algumas medidas tratam da melhoria do ensino superior com maior atenção e incentivos à pesquisa, empreendedorismo e

\footnotetext{
${ }^{4}$ Isto porque em 2021 o Partido Comunista Chinês completa 100 anos e atingir essa conquista simbólica seria um grande passo para o "Sonho Chinês" divulgado por Xi Jinping, que consiste em atingir uma "sociedade próspera em todos os aspectos" até 2049, centenário da Revolução Comunista (NPC, 2016).

${ }^{5}$ Alguns dos objetivos e medidas expostos pelo $13^{\circ}$ Plano são: dobrar o PIB de 2010 até 2020; retirar 70 milhões de chineses da pobreza; diminuir $15 \%$ do consumo nacional de energia; diminuir as taxas de desemprego urbano, criando milhões de novas oportunidades; aumentar 1 ano da expectativa média de vida; reconstruir e modernizar habitações urbanas; investir 2,5\% do PIB em Pesquisa e Desenvolvimento; $60 \%$ de contribuição da Ciência e Tecnologia para o crescimento econômico; entre outros. Segundo exposto no Plano, os próximos 5 anos serão caracterizados pela inovação, coordenação e cuidado com o ambiente, abrindo e compartilhando a economia chinesa para o mundo, com o crescimento médio-alto e a atualização da indústria como sendo os dois maiores objetivos econômicos (NPC, 2016, p. 23).
} 
educação inovadora a fim de contribuir para o propósito nacional de inovação tecnológica (MOE, 2010).

Ainda que sejam diretrizes para setores distintos do governo chinês, o conceito de inovação é amplamente utilizado ao se tratar das perspectivas e objetivos chineses para os próximos anos de construir um "país inovador" e rico em talentos para se desenvolver social e economicamente (KAO, 2007). Desta forma, a inovação chinesa antes era conhecida como baseada em mudanças organizacionais, uso de conhecimento tecnológico de outros países, larga escala e custos reduzidos, a fim de tornar o valor de seus produtos manufaturados mais atrativos no exterior.

Recentemente, o governo chinês publicou alguns planos nacionais para o desenvolvimento da Ciência e Tecnologia, onde explicita seus objetivos para construir um sistema de inovação tecnológica com as empresas como atores principais e as indústrias, universidades e institutos de pesquisa estritamente ligados, neste contexto, a fim de promover uma melhor integração entre os atores e subsistemas nacionais.

No entanto, ainda que os papéis e interações dos atores do sistema nacional de inovação da China dependam das decisões do governo central, há certa autonomia entre as províncias para a tomada de decisão sobre como agir para atingir os objetivos nacionais (SONG, 2013; BREZNITZ; MURPHEE, 2011).

Concomitantemente com o processo de desenvolvimento da Ciência e Tecnologia, desde o início do processo de Reforma e Abertura (1978), o país vem buscando reformar seu sistema educacional, na medida em que estratégias de diversificação de financiamento, descentralização administrativa, e expansão em escala do Ensino Superior vêm ocorrendo desde então.

Neste universo, diferentes instituições de ensino superior têm recebido incentivos financeiros, em decorrência de pressão para uma melhora da qualidade do ensino e pesquisa, ao mesmo tempo em que estreita as relações entre o ensino superior e o desenvolvimento econômico (CAI; YAN, 2015).

Em um estudo quantitativo realizado por Hu e Mathews (2008), apresentou-se como principal diferença entre a China e outros países asiáticos - o que também é estudado pelos autores - o fato de que as universidades chinesas têm uma maior participação nas atividades de inovação do país, ao mesmo tempo em que o setor público teve papel menos relevante do que se esperaria, existindo variação, entretanto, entre diferentes províncias (HU; MATHEWS, 2008). 
A partir da contextualização acima, a pesquisa tem como principal pergunta a ser respondida: como ocorre a participação das instituições de ensino superior (IES) no sistema nacional de inovação da China? Neste âmbito, o objeto da pesquisa é analisar a contribuição das IES para o Sistema de Inovação da China, ou seja, se os indicadores de inovação são afetados por maiores ou menores números de instituições de ensino superior (estudantes matriculados, graduados, ou professores, por exemplo).

Há na literatura argumentos de que a educação, e mais especificamente as universidades, têm papel importante nos processos de inovação de um país ou região, já que fornecem tanto resultados de pesquisas científicas quanto profissionais e cientistas capacitados para desenvolver novas tecnologias (PARK, 2013; KRUCKEN, 2013; FORAY; LISSONI, 2010; LUNDVALL, 2010; MOWERY; SAMPAT, 2005; ETZKOWITZ; LEYDESDORFF, 2000, entre outros).

Tendo em vista na literatura a participação das IES nos Sistemas Nacionais de Inovação (mais especificamente a que trata sobre o caso da China), planos do governo chinês para a pauta, e a análise do banco de dados elaborado, neste contexto, o objetivo geral desta pesquisa é compreender: de que forma a participação das IES contribui para o crescimento dos outputs de inovação (patentes) do sistema nacional de inovação da China, dado que o foco é observado entre o período que se desprende de: 2006 à 2017.

O recorte temporal justifica-se pela data do Plano Nacional de Médio-Longo Prazo para Desenvolvimento da Ciência e Tecnologia (2006-2020) que dá início a uma série de publicações e políticas que visam tanto uma maior integração entre educação e C\&T quanto à necessidade da China desenvolver novas tecnologias a partir de inovações de origem nacional.

Isto posto, ainda que a maioria dos planos tenha como data de término o ano de 2020, a análise da pesquisa terá como foco até 2017, tendo em vista o prazo para a conclusão da pesquisa e a disponibilidade de dados estatísticos.

Por meio da investigação da participação das IES no sistema nacional de inovação chinês e das mudanças que recentemente foram propostas através dos planos governamentais, os objetivos específicos da pesquisa são: compreender a inserção das IES no processo de inovação da China; verificar em que medida essas interações ocorrem; e identificar características regionais que estão associadas a uma maior ou menor participação das IES no Sistema Nacional de Inovação, a partir de casos selecionados. 
Tendo como argumento geral o fato de que a China está criando um modelo de desenvolvimento sem precedentes simultâneo à sua própria trajetória, na medida em que carrega consigo novas políticas (como as econômicas, de desenvolvimento, e de inovação), as principais contribuições da pesquisa se dariam por uma maior compreensão das relações entre as IES e o sistema de inovação do país através de uma análise quantitativa das principais variáveis relacionadas à participação das IES acompanhada de um aprofundamento qualitativo a partir de estudos de caso de províncias selecionadas.

Devido ao grande número de IES na China e grandes diferenças entre as suas províncias, bem como para contribuir com a confiabilidade da análise dos dados, serão utilizados dados provinciais. Identificou-se uma lacuna na literatura sobre as IES como atores de inovação no SNI chinês, e, ainda que diversos autores tratem de forma mais geral sobre a temática. Deste modo, não foi identificado até o momento algum trabalho que se utilize da mesma abordagem de métodos mistos nos últimos anos (MOK, YUE, 2015; ZHA, HAYHOE, 2015; CAI, YAN, 2015; BREZNITZ, MURPHREE, 2011; HU; MATHEWS, 2008).

Levando em consideração a importância de estudos mais específicos para complementar a literatura existente sobre sistemas nacionais de inovação e os papeis de diferentes atores e instituições dentro desses sistemas, o caso do sistema nacional de inovação chinês e, mais especificamente, o papel que as IES chinesas vêm desempenhando evidencia-se atual e relevante, uma vez que é necessário observar a projeção da China na economia mundial. Nesta conjuntura, também observa-se a conta dos diversos planejamentos e transformações que o governo chinês vem buscando nos últimos anos.

Dentre as principais limitações está a ausência de dados desagregados sobre as patentes no banco de dados. Nesta situação, ainda que existam relatórios oficiais com maiores especificações sobre a origem e caráter das patentes, foram encontradas poucas universidades que divulgam informações sobre suas patentes concedidas, o que poderia facilitar na análise se fôssemos analisar por que certas IES inovam e outras não. Outra limitação é o limite de tempo e de orçamento, que impedem um estudo de caso mais aprofundado, que poderia ser realizado em alguma IES, ou entre diferentes IES na China.

Após apresentar a proposta de pesquisa de forma mais geral, faz-se necessário o aprofundamento teórico e bibliográfico. A proposta de capítulo 1 contém uma 
abordagem mais aprofundada dos conceitos de inovação, sistema nacional de inovação, e as instituições de ensino superior como atores de inovação. Na proposta de capítulo 2 (seção 3), há a apresentação da metodologia, do banco de dados elaborados, e das estatísticas descritivas das principais variáveis.

\section{INOVAÇÃO, SISTEMAS NACIONAIS DE INOVAÇÃO E INSTITUIÇÕES DE ENSINO SUPERIOR}

\subsection{O que é Inovação?}

O conceito mais difundido de inovação foi concebido pelo economista austríaco Joseph A. Schumpeter, no começo do século XX, que tem como suas maiores contribuições para os estudos sobre Inovação as obras "Teoria do Desenvolvimento Econômico" originalmente publicado em 1912, em alemão e "Capitalismo, Socialismo e Democracia” de 1942.

Ainda que a Inovação como área de estudos tenha ganhado força somente nas últimas décadas do século XX, o conceito schumpeteriano segue sendo utilizado como referência basilar pela literatura. Para Schumpeter (1997), inovações seriam novas combinações de materiais e forças já existentes na economia e podem se referir a

1) Introdução de um novo bem [...] ou de uma nova qualidade de um bem. 2) Introdução de um novo método de produção [...] 3) Abertura de um novo mercado [...] 4) Conquista de uma nova fonte de matériasprimas ou bens semimanufaturados [...] 5) Estabelecimento de uma nova organização de qualquer indústria, como a criação de uma posição de monopólio (por exemplo, pela trustificação) ou a fragmentação de uma posição de monopólio (SCHUMPETER, 1997, p.76).

Essas inovações, quando introduzidas na atividade econômica, produzem mudanças qualitativamente superiores das pequenas alterações cotidianas, levando ao rompimento do equilíbrio econômico. A evolução econômica seria, então, causada por rupturas e descontinuidades da situação econômica por meio da introdução de novidades (inovações) ao funcionamento do sistema. A inovação, para Schumpeter, seria uma força dinâmica transformadora contínua das estruturas sociais, institucionais e econômicas (FAGERBERG; FOSAAS; SAPPRASERT, 2012). 
Outras ideias centrais para a literatura atual sobre Inovação também tem como base as duas obras de Schumpeter, como é o caso da inovação como novas combinações de conhecimentos e recursos existentes, a diferenciação entre invenções e inovações, e o interesse nos seus impactos sociais e econômicos (FAGERBERG; FOSAAS; SAPPRASERT, 2012).

A inovação seria, então, uma constante mudança e renovação, como um processo de "Destruição Criadora", assim como posto por Schumpeter (1961), consistindo em uma contínua necessidade de novas e mais eficientes maneiras de produzir (PARK, 2013). Esse processo seria essencial ao capitalismo, pressupondo-se que ao conseguir mais e/ou melhores resultados com menos esforços é possível revolucionar a estrutura econômica de dentro para fora, continuamente destruindo a antiga e criando uma nova (SCHUMPETER, 1961).

Visão, esta, já introduzida por Marx, em 1848, ao afirmar que "[a] burguesia só pode existir com a condição de revolucionar incessantemente os instrumentos de produção e, com isso, todas as relações sociais" (MARX; ENGELS, 1998, p.43). Seu pressuposto de que novas forças produtivas conflitam com as relações de produção existentes servem como base para os estudos de sistemas de inovação (LUNDVALL, 2010).

Ao se entender a inovação não apenas como grandes descobertas realizadas a partir de atividades de alta tecnologia (incluindo, assim, o melhoramento de produtos, processos, organizações, etc.), pode-se considerar que inovação é um aspecto da grande maioria das atividades econômicas. Isso a torna relevante para os países considerados em desenvolvimento, assim como já o é para os desenvolvidos. (FAGERBERG; SRHOLEC; VERSPAGEN, 2010). Há diferentes abordagens sobre como a questão da inovação se relaciona com o crescimento e o desenvolvimento econômico, tratadas por distintas vertentes.

Para os economistas políticos clássicos as diferenças no crescimento econômico eram vistas como um reflexo de distintas taxas de acumulação de capital, focando na acumulação de capital por trabalhador para explicar diferenças na produtividade e nos ganhos (FAGERBERG et al., 2010; SOETE; VERSPAGEN; WEEL, 2010). A vertente econômica clássica e neoclássica vê a inovação como o ato de criar ativos e experimentos de mercado, como estratégia de negócios ou decisões de investimentos a fim de melhorar a eficiência ou desenvolver produtos (OCDE, 1997). Adam Smith na obra "A Riqueza das Nações" (1776) trata na introdução sobre o papel das inovações, 
como as melhorias nos maquinários através das estratégias dos trabalhadores em facilitar o manejo das máquinas, e daqueles que as produzem, que ganham experiência na produção e aumentam o grau de "ciência" aplicada às máquinas de acordo com suas experiências (LUNDVALL, 2010).

Friedrich List, por sua vez, foi um dos primeiros economistas, em 1841, a entender como crucial as interações entre ciência, tecnologia e habilidades para o crescimento das nações, e a argumentar sobre a necessidade da indústria estar ligada às instituições de ciência e educação, onde o governo teria o papel de fornecer a infraestrutura que contribuiria para o avanço tecnológico (SOETE; VERSPAGEN; WEEL, 2010; LUNDVALL, 2010). Considera-se que List tenha antecipado as teorias contemporâneas de "Sistemas Nacionais de Inovação".

Robert Solow (1956) na sua "teoria neoclássica do crescimento" inclui o progresso tecnológico como fator exógeno ao modelo de crescimento neoclássico. Nesse modelo, o aumento da produtividade é resultado do aumento de capital que cada trabalhador opera. Entretanto, com o tempo a razão entre capital e trabalho, que resulta na produtividade, tende a uma constante, anulando o crescimento da produtividade. $\mathrm{O}$ fator exógeno do progresso tecnológico, portanto, permitiria "saltos" na razão capitaltrabalho que proporcionaria o crescimento do PIB per capita por um período de tempo mais extenso (SOLOW, 1956; FAGERBERG; SRHOLEC; VERSPAGEN, 2010).

O historiador econômico Gerschenkron (1962), a partir do pressuposto de que alguns países estão na fronteira tecnológica, enquanto outros ficaram para trás (lag behind) argumenta que diferenças no desenvolvimento econômico dos países são causadas principalmente por diferenças tecnológicas entre eles, mas que o processo de catch-up tecnológico não é automático, necessitando de esforços organizações e mudanças institucionais para ocorrer (GERSCHENKRON, 1962; FAGERBERG; FOSAAS; SAPPRASERT, 2012). Para o desenvolvimentista brasileiro Celso Furtado, o desenvolvimento econômico tem como pressuposto a inovação, quando o caracteriza como sendo

um processo de mudança social pelo qual um número crescente de necessidades humanas - preexistentes ou criadas pela própria mudança - são satisfeitas através de uma diferenciação no sistema produtivo decorrente da introdução de inovações tecnológicas (FURTADO, 1964, p.29). 
A partir das vertentes apresentadas, diversas abordagens acerca dos efeitos da inovação na economia, explicações sobre diferenças tecnológicas entre países e outros aspectos referentes aos processos de inovação foram desenvolvidas (OCDE, 1997; FAGERBERG; SRHOLEC; VERSPAGEN, 2010; FAGERBERG; SRHOLEC, 2008). Contudo, o aprofundamento nessas abordagens não faz parte do escopo da pesquisa.

A fim de apresentar brevemente o estado da arte dos estudos sobre inovação e aprofundar a abordagem que diz respeito ao nosso trabalho, a próxima seção trará algumas abordagens utilizadas nos estudos da área da Inovação e mais profundamente a dos Sistemas Nacionais de Inovação.

\subsection{Estudos sobre Inovação e a abordagem sistêmica}

Assim como novas especialidades áreas do conhecimento se desenvolvem de tempos em tempos em resposta a novos problemas e desafios que demandam novos conhecimentos, os estudos sobre Inovação se desenvolveram a partir da necessidade de se compreender os avanços tecnológicos, as diferenças tecnológicas e de desenvolvimento existentes entre os países, bem como os fatores que as explicam e as consequências econômicas e sociais das inovações.

A área recebeu maior atenção à época da Segunda Guerra Mundial, quando policymakers passaram a se interessar em Pesquisa \& Desenvolvimento e inovações como possibilidade de melhoria do progresso militar, inicialmente nos Estados Unidos, como aparece na importante obra de Vannevar Bush (1945). Entretanto, havia pouca consistência entre os trabalhos produzidos até o início os anos 1960, com exceção das obras de Schumpeter, tendo em vista o foco distinto dos autores e até mesmo concepções distintas do que seria inovação (FAGERBERG; FOSAAS; SAPPRASERT, 2012).

Entre os anos de 1970 e 1980 os estudos sobre Inovação entraram em fase de crescimento com importantes publicações, nos EUA e Inglaterra. Um dos fatores que contribuíram para o florescimento da área foi o estabelecimento do primeiro centro de pesquisa interdisciplinar, o Science Policy Research Unit (SPRU), em 1966, na Universidade de Sussex, que evoluiu para um "hub" de pesquisa em inovação, atraindo estudiosos de diversas áreas do conhecimento. A ênfase na multi-interdisciplinaridade propiciou o desenvolvimento de um framework conceitual e teórico mais coerente, 
característica essa que também facilitou a aceitação da nova disciplina no campo acadêmico (FAGERBERG; FOSAAS; SAPPRASERT, 2012).

Nos anos finais da década de 1980 tem início a fase de maturação da área, com a emergência de periódicos, associações profissionais especializadas e um aumento na incidência de estudos sobre Inovação Organizacional. Um novo ramo da literatura, que particularmente nos interessa mais, também surge nesse mesmo período, os "Sistemas de Inovação", focado mais especificamente no papel da inovação no desenvolvimento nacional e regional (FAGERBERG; FOSAAS; SAPPRASERT, 2012).

Entre as obras de referência da área destacam-se o Handbook of the Economics of Innovations, de Hall e Rosenberg (2010), e The Oxford Handbook of Innovation, de Fagerberg, Edquist e Nelson, (2005). Entre as principais contribuições destacam-se Joseph Schumpeter (1912; 1942), Christopher Freeman (1987), Nathan Rosenberg (1982), Bengt-Ake Lundvall (1992), Richard Nelson (1993) e Nelson R. e Winter S (1982) (FAGERBERG; FOSAAS; SAPPRASERT, 2012). Os usuários da literatura concentram-se nos EUA e Europa, nas principais universidades estadunidenses (Harvard, Stanford, MIT, Berkeley) e no SPRU, e advêm principalmente das Ciências Sociais e Humanidades, Economia e Administração (FAGERBERG; FOSAAS; SAPPRASERT, 2012).

Dentre as contribuições mais recentes, a partir do final dos anos 1980, importantes trabalhos consideraram de grande importância a interação sistêmica entre diferentes componentes que culminavam nas invenções, inovações e mudanças tecnológicas (SOETE et al., 2010). Lundvall (1992) e Nelson (1993), focados nas questões "macro", a níveis regionais, nacionais e internacionais, utilizaram essa abordagem sistêmica para estudar o fenômeno da inovação. Freeman foi o primeiro a utilizar a noção de "Sistema Nacional de Inovação" (1987), que traz em posição de destaque o estado como agente coordenador (SOETE; VERSPAGEN; WEEL, 2010; FAGERBERG; FOSAAS; SAPPRASERT, 2012). Abordagem esta que desde seu início atraiu o interesse de policymakers e pesquisadores.

Como citado anteriormente, ao criticar a visão dos economistas clássicas sobre o progresso tecnológico ser visto apenas como uma forma de acumulação de capital, Friedrich List (1841) destacou o papel das interações sistêmicas entre ciência e tecnologia para o crescimento dos países (SOETE; VERSPAGEN; WEEL, 2010; LUNDVALL, 2010). Suas análises indicavam a responsabilidade governamental para a educação e treinamento da mão-de-obra, assim como a infraestrutura necessária para o 
desenvolvimento da indústria, sendo ele considerado um antecipador das teorias de “sistemas de inovação" (SOETE; VERSPAGEN; WEEL, 2010; LUNDVALL, 2010).

Análises históricas sobre o papel dos estados na coordenação de políticas do longo prazo para a indústria, economia, e ciência \& tecnologia deram subsídios para o desenvolvimento do conceito de Sistema Nacional de Inovação (SNI), por Freeman, Lundvall e Nelson (SOETE et al., 2010). A expressão "sistema nacional de inovação" se tornou popular para descrever esses elementos organizacionais que proporcionam o desenvolvimento de inovações dentro de um país. Contudo, perspectivas como sistemas nacionais, regionais ou setoriais de inovação são variantes de uma mesma definição geral de "sistemas de inovação" (EDQUIST, 2005).

A ideia central da teoria moderna dos sistemas de inovação é a noção de que o que é considerado inovação ser, em realidade, o resultado de um processo interativo que envolve diversos atores, governados pelas forças de mercado, mas também por instituições não comerciais, tendo em vista que a eficiência observada no nível macro depende do comportamento individual dos atores, isto é, há, então, diversos problemas de coordenação (SOETE; VERSPAGEN; WEEL, 2010). Na visão dos seus principais proponentes observa-se um sistema de inovação, ou mesmo, um processo contínuo onde diferentes instituições e organizações têm papeis centrais na geração de inovação e mudança tecnológica (SOETE; VERSPAGEN; WEEL, 2010).

Freeman (1987), na sua obra sobre o desenvolvimento econômico e tecnológico do Japão, foi o primeiro autor a utilizar o termo Sistema Nacional de Inovação, definindo-o como "a rede de instituições nos setores público e privado das quais as atividades e interações iniciam, importam, modificam e difundem novas tecnologias" (FREEMAN, 1987, p.1, apud EDQUIST, 2005, p. 183). Sua análise histórica do caso japonês, e partindo dos pressupostos da teoria da inovação, teve como foco a organização da Pesquisa \& Desenvolvimento, o papel do Ministério do Comércio Internacional e Indústria (MITI), e as relações entre empresas japonesas (SOETE; VERSPAGEN; WEEL, 2010; LUNDVALL, 2010; EDQUIST, 2005). Em consonância com a visão de List (1841), os policymakers japoneses contribuíram para o processo de catch-up do país ao escolher indústrias estratégicas e o fornecimento de vantagens comparativas para servir de base ao crescimento delas (SOETE; VERSPAGEN; WEEL, 2010).

Lundvall (1992), ainda que com uma visão similar a de Freeman, dá ênfase a uma estrutura institucional nacional, onde empresas e outras organizações operam e que 
são de suma importância para o processo de introdução e difusão das inovações na economia. Sendo mais teórico em relação a outros autores dos sistemas de inovação, dado que há três grandes temas que são tratados e teorizados por Lundvall, que seriam: os tipos de atividades que induzem à inovação, ou seja, aprendizado e pesquisa; as naturezas da inovação, incremental (gradual e contínua) ou radical; as instituições não comerciais, como as trocas de informações entre usuários e produtores de inovação; e as instituições relacionadas a costumes e cultura, desenvolvidas historicamente e que regulam indiretamente o comportamento dos atores (SOETE; VERSPAGEN; WEEL, 2010; LUNDVALL, 2010; EDQUIST, 2005).

A obra de Nelson (1993), todavia, tem foco mais empírico, com uma coletânea de estudos de caso com descrições históricas de sistemas nacionais de inovação de diversos países, na intenção de demonstrar as diferenças de competitividade entre os SNIs a partir de seus arranjos de atores, incentivos e padrões organizacionais. Seu ponto de mais interesse é a produção de conhecimento e de inovação.

Neste contexto, Nelson e Rosenberg (1993), estudou com ênfase nas instituições que servem de base para $\mathrm{P} \& \mathrm{D}$, ao mesmo tempo em que argumentam como a tecnologia molda as agendas de pesquisa e, neste pensamento, questionam também de que o modo o sistema universitário é organizado, influenciando no funcionamento do sistema de inovação (SOETE; VERSPAGEN; WEEL, 2010; NELSON; ROSENBERG, 1993).

Uma definição mais ampla de "sistema (nacional) de inovação" é entendido por Charles Edquist como sendo os determinantes dos processos de inovação, ou seja, todos os fatores econômicos, sociais, políticos, organizacionais, institucionais importantes que influenciam o desenvolvimento, difusão e uso de inovações (EDQUIST, 1997).

Dentre os pontos fortes de se utilizar a abordagem dos sistemas de inovação, estão: inovação e processos de aprendizagem como centro do foco; perspectiva holística e interdisciplinar; emprego de perspectivas históricas e evolucionárias; ênfase na interdependência e não-linearidade dos processos; engloba tanto as inovações de produtos como de processos e suas subcategorias; e a ênfase no papel das instituições (EDQUIST, 2005).

Os pontos negativos seriam, principalmente, a difusão conceitual tanto do que pode ser inovação, quanto do que seriam as instituições, e a dificuldade de se delimitar quais seriam os componentes e relações de cada sistema, tendo em vista que há distinções nas noções do que seria um sistema de inovação (SOETE; VERSPAGEN; WEEL, 2010; EDQUIST, 2005; FAGERBERG, 2005). 
As organizações de um SNI podem ser entendidas a partir do caráter que possuem, como: órgãos políticos (ministérios, conselhos nacionais); órgãos burocráticos (agências e escritórios públicos); órgãos regulatórios (controlam padrões, normas e certificações); órgãos sociais (associações de profissionais e acadêmicos); órgãos educacionais (escolas e universidades); órgãos sem fins lucrativos (laboratórios governamentais, centros técnicos ou estações experimentais); empresas com fins lucrativos (consórcios, empresas de $\mathrm{P} \& \mathrm{D}$, joint ventures); e órgãos com o objetivo de fazer a ponte entre os demais (centros de inovação; câmaras de comércio, associações industriais, unidades universitárias ligadas à indústria) (NORTH, 1994 apud MEEUS; OERLEMANS, 2005).

Enquanto que as instituições estruturantes dos processos de inovação podem ser formais (leis sobre patentes e propriedade intelectual, alocação de recursos para ciência, normas e padrões técnicos, etc.) ou informais (normas de conduta, cultura, convenções sociais) (GALLI; TEUBAL, 1997).

Ainda que existam divergências nos entendimentos do que são os sistemas (nacionais) de inovação, essa abordagem ganhou força na literatura e nos debates políticos nas últimas décadas, mas ainda depende de desenvolvimento. Há a necessidade, contudo, de se demonstrar como os arranjos institucionais e organizacionais dentro dos SNIs influenciam no desempenho de inovação, corrente que vem sendo desenvolvida por alguns autores interessados nas interações das universidades dentro dos SNIs (SOETE et al., 2010; MOWERY; SAMPAT, 2005), na medida em que a inserção da presente pesquisa na abordagem dos sistemas nacionais de inovação, se vê necessária seu aprofundamento na questão das instituições de ensino superior como atores nos sistemas nacionais de inovação.

\subsection{Instituições de Ensino Superior como atores de Inovação}

A contribuição das Instituições de Ensino Superior (IES) ${ }^{6}$ nos processos de inovação tem sido debatida desde que os estudos sobre inovação passaram a se desenvolver, sendo um assunto discutido em variadas regiões e sistemas nacionais de inovação pelo mundo (NELSON, 1993). Para Park (2013), de um lado, as universidades

\footnotetext{
${ }^{6}$ Os termos "instituições de ensino superior" e "universidades" são utilizados ao longo do texto de acordo como é tratado pelos próprios autores, sendo que, para a presente pesquisa e tratando-se de dados sobre a China, o termo a ser utilizado é "instituições de ensino superior", já que os dados trabalhados também incluem instituições e estudantes de instituições de ensino superior que não são consideradas como universidades na China.
} 
e outras IES tem a tarefa de educar e treinar a mão de obra para ser capaz de suprir as demandas do mercado de trabalho de uma economia do conhecimento. Por outro lado, agem como instituições centrais de criação de novas e originais ideias, e, dentre outros atores, ainda têm papel fundamental para a produção de conhecimento. Neste âmbito, as IES, ocupam posição central na sociedade global do conhecimento, tendo em vista suas contribuições para os processos de inovação e desenvolvimentos econômico e social (PARK, 2013).

Neste contexto, o papel das pesquisas desenvolvidas pelas universidades para os processos de inovação é discutido desde os anos 1950, com o modelo linear proposto por Vanevar Bush, mas passou por mudanças ao longo das décadas. Seguindo esse modelo, o financiamento de pesquisa básica a ser desenvolvida nas universidades seria o necessário e suficiente para promover a inovação. Entretanto, a experiência japonesa já se mostrou diferente décadas atrás (MOWERY; SAMPAT, 20015)

Antes as universidades eram compreendidas como provedoras de conhecimento básico, e mais atualmente é entendida de forma mais abrangente e complexa, com uma participação mais ativa e empreendedora tão importante quanto a pesquisa básica (KRÜCKEN, 2013).

A atribuição da participação das IES através das pesquisas que realizam foi se alterando ao longo do tempo. De início, até os anos 1970, as pesquisas eram tidas como recursos essenciais para as inovações industriais. Mais recentemente as fronteiras entre as pesquisas em universidades e aplicações industriais passaram a ser menos visíveis, e dependentes das abordagens conceituais utilizadas pelos policymakers de cada país e região (KRÜCKEN, 2013).

Ainda com diferenças no entendimento, um crescente número de governos nacionais vem buscando utilizar suas universidades como instrumentos de mudança e desenvolvimento de uma economia industrial e/ou em desenvolvimento, para uma economia baseada no conhecimento (MOWERY; SAMPAT, 2005). Ao combinar pesquisa básica com ensino - ambas as atividades de grande relevância econômica - as evidencia-se neste movimento das universidades um protagonismo crucial, ainda que indireto, no crescimento da produtividade e expansão da indústria e dos serviços. Enquanto que contribuem diretamente para o processo de inovação ao prover para a indústria e serviços soluções ou aparatos tecnológicos, e ao se envolver em atividades de pesquisa aplicada (FORAY; LISSONI, 2010). 
De acordo com o modelo linear de inovação, que até os anos 1980 foi a abordagem dominante ao se estudar a relação universidade e inovação, as universidades seriam responsáveis pela pesquisa básica, enquanto a pesquisa aplicada e o desenvolvimento ficariam a cargo da indústria. Nesse modelo, a pesquisa feita pelas universidades não implicaria em uma contribuição direta para a inovação (KRUCKEN, 2013). Entretanto, a transferência dos resultados das pesquisas além de não ocorrer mais de forma linear, também não ocorre em sentido único.

Ou seja, os pesquisadores acadêmicos passaram a engajar-se na cooperação com parceiros industriais e redefinir suas agendas de pesquisa também de acordo com as tendências do mercado, assim como as fronteiras entre a pesquisa básica e atividades de comercialização se tornaram menos claras. As interações entre universidades e outros atores nos processos de inovação passaram a ser mais complexas e híbridas (KRUCKEN, 2013).

O modelo de sistema nacional de inovação chamado Triple Helix, de Etzkowitz e Leytesdorff (2000), dá ênfase na necessidade crescente de interação entre os atores do sistema, referentes a academia/universidades, indústria, e estado/governo (SONG, 2013; CAI et al., 2015; LUNDVALL, 2010; ETZKOWITZ; LEYDESDORFF, 2000). Os três elementos chave seriam os componentes do sistema (atores nas esferas da universidade, indústria e governo); as relações entre os três setores (transferência de tecnologia, colaboração, networking); e as funções do sistema (geração, difusão e utilização de conhecimento e inovação) (CAI et al., 2015). As universidades, então, aparecem como pilares essenciais para os sistemas.

Houve algumas tentativas de encorajar as universidades a contribuírem mais diretamente com o processo de inovação, tornando os conhecimentos produzidos em patentes e produtos comercializáveis, sendo a mais conhecida e importante delas o Bayh-Dole Act, de 1980, nos Estados Unidos. Foi a tentativa do governo estadunidense de tornar as conquistas científicas de suas instituições de pesquisa em inovações ao ceder às universidades e outras organizações com direitos de propriedade intelectual e possibilidades exclusivas para licenças (FORAY; LISSONI, 2010; MOWERY; SAMPAT, 2005; KRUCKEN, 2013).

Desde os anos 1970 há essa tendência dos governos em tentar aumentar a transferência dos avanços em pesquisas acadêmicas para a indústria e facilitar a aplicação dos resultados nas empresas nacionais, como estratégia para melhorar o desempenho econômico nacional (MOWERY; SAMPAT, 2005). Na já mencionada 
economia do conhecimento, os sistemas nacionais de educação superior (incluindo as universidades e outras instituições) podem ser um recurso estratégico, mas apenas se os laços com a indústria forem fortalecidos e a transferência de tecnologia incentivada e apoiada. As tentativas, entretanto, muitas vezes, ocorrem como forma de garantir o direito à propriedade intelectual individual das inovações, e não nas raízes da relação indústria-universidade, mais abrangente e complexa (MOWERY; SAMPAT, 2005).

A participação das universidades de acordo com a abordagem dos sistemas de inovação, tratada na seção anterior, pode ser observada quando são analisadas as atividades e funções dos sistemas de inovação. Pode ocorrer tanto na função e atividade de Pesquisa \& Desenvolvimento, com as universidades e instituições de pesquisa, quanto na Construção de Competências que ocorre nas escolas e universidades, levando à criação do que é conhecido como "capital humano". Desse modo, as universidades são atores cruciais nos sistemas nacionais de inovação, ao representar a capacidade de geração e absorção de um SNI (EDQUIST, 2005; MEEUS; OERLEMANS, 2005).

Alguns dos outputs econômicos importantes das universidades são a informação científica e tecnológica, equipamentos e instrumentalização, técnicas ou capital humano, redes de capacidades científicas e tecnológicas e protótipos para novos produtos e processos (MOWERY; SAMPAT, 2005).

Andersson, Quigley e Wilhelmsson (2009) demonstram em seu artigo sobre urbanização, produtividade e inovação como os investimentos em educação superior estão relacionados a uma maior produtividade e criatividade em diferentes regiões da Suécia. Os autores encontraram evidências de que nas regiões onde se tem mais investimentos em universidades, há mudanças na produtividade e também na obtenção de patentes. De acordo com os resultados, regiões com maior número de pesquisadores ligados à universidades apresentam aumento no número de patentes obtidas.

Outros autores como Griliches (1984), Acs et al. (2002), Jaffe (1989), Varga (1998; 2000), Fischer e Varga (2003) também desenvolveram pesquisas empíricas onde os resultados demonstraram a existência de relações, ainda que com características e intensidades diferentes, entre a participação das universidades e os inputs (investimentos em P\&D) e outputs (patentes) de inovação.

Uma importante lacuna nas pesquisas sobre o papel das universidades nos sistemas nacionais de inovação, também tida como uma das oportunidades, é a necessidade de desenvolvimento de melhores indicadores quantitativos sobre a dimensão e importância dessa participação (MOWERY; SAMPAT, 2005). A falta de 
dados específicos sobre a participação das universidades que possibilitam comparações ao longo do tempo ou entre países prejudica esse desenvolvimento teórico, conceitual e metodológico para se analisar as universidades como agentes econômicos. Argumentase também que as relações entre trabalhos conceituais e empíricos da área não são consistentes (FAGERBERG; SRHOLEC, 2008).

Devido a sua perspectiva holística e evolucionária, englobando produtos e processos de inovação, com ênfase na interdependência, não linearidade e o papel das instituições, a abordagem de Sistemas de Inovação também foi utilizada por diversos autores para analisar a inovação na China (FAN, 2014).

A presente pesquisa, entretanto, não tem como objetivo preencher essa lacuna ainda que possa contribuir para o desenvolvimento dos estudos sobre a participação das universidades no sistema nacional da China, e indiretamente para outros possíveis trabalhos. Na seção seguinte apresenta-se um estudo mais aprofundado do caso chinês.

\section{O SISTEMA NACIONAL DE INOVAÇÃO DA CHINA E AS UNIVERSIDADES}

\subsection{Sistema de Inovação da China}

Antes de 1980, a China tinha um sistema nacional de inovação semelhante ao de outras economias planificadas, como a União Soviética e a Índia, caracterizado pela completa separação das atividades de pesquisa, educação, e atividades manufatureiras nas instituições públicas de pesquisa, universidades e empresas estatais (XUE, 1997). Desde a reforma econômica, a partir de 1978, o governo chinês começou a transformar o modelo soviético.

Em 1985, uma resolução do Comitê Central do Partido Comunista Chinês sobre a reforma estrutural do sistema de ciência e tecnologia foi promulgada, servindo como base para a mudança do modelo soviético de sistema de inovação (MOTOHASHI; YUN, 2007).

Nesse modelo, as atividades de ciência e tecnologia e inovação eram separadas das atividades industriais. A transferência de tecnologias desenvolvidas em institutos de 
P\&D também era controlada por diferentes níveis de governos. Como resultado desse modelo, as instituições públicas de pesquisa não tinham incentivos para entender as necessidades das empresas por tecnologia, enquanto que as empresas estatais estavam concentradas nas atividades produtivas sem incentivos à inovação.

Dentre as medidas de transformação, o governo reduziu o financiamento institucional para as instituições públicas de pesquisa, afim de induzi-las a conduzir P\&D orientado ao mercado através das indústrias e universidades, mas também ofereceu incentivos financeiros para comercializar os resultados de $\mathrm{P} \& \mathrm{D}$, especialmente pelo Torch Program, que focava na industrialização de alta tecnologia (FAN, 2014). Ele facilitou regulações, proveu suporte para construção de infraestrutura para atrair empresas estrangeiras de alta tecnologia, ao mesmo tempo em que encorajou o estabelecimento de empresas locais de alta-tecnologia em zonas especiais pela China. (CHEN; KENNEY, 2007). Durante o período de transição de 1996 a 2002, as atividades de C\&T das empresas aumentaram significativamente inovação (MOTOHASHI; YUN, 2007).

Um dos principais objetivos das recentes iniciativas políticas é resolver estes problemas de incentivo tanto do lado da indústria, quanto do lado da ciência, afim de estimular inovações baseadas nos outputs de pesquisa dos setores científicos. inovação (MOTOHASHI; YUN, 2007).

Liu e White identificaram cinco atividades fundamentais do sistema nacional de inovação chinês, sendo elas: pesquisa (básica, aplicada, engenharia); implementação (manufatura); uso final (clientes dos produtos ou resultados); ligações (reunindo conhecimentos complementares); e educação (LIU; WHITE, 2001). SNI chinês na fase de transição tinha duas características distintas: a inclusão de novos atores para cada atividade fundamental, e a diversificação de atividades dos atores primários.

Para as atividades educacionais, enquanto as universidades ainda são os principais atores primários, também estenderam suas atividades para $\mathrm{P} \& \mathrm{D}$ e manufatura. A China rapidamente aumentou a escala do seu ensino superior expandindo as universidades existentes e estabelecendo mais instituições de ensino superior, o que aumentou naturalmente o número de graduados em cursos de ciência e tecnologia. (FAN, 2014). 
As relações universidade-indústria são variadas e podem incluir: ligações relacionadas ao mercado de trabalho; ligações para criação, aquisição e disseminação de conhecimento, e ligações para criar novas empresas. As universidades são as principais instituições educacionais e de treinamento onde os estudantes e profissionais educados e treinados adquirem conhecimentos e habilidades e se tornam parte da mão de obra na economia regional (CHEN; KENNEY, 2007).

Sob o modelo soviético de Sistema de inovação, as atividades de C\&T costumavam ser conduzidas por universidades e instituições públicas de pesquisa, separadas das empresas estatais. Assim, ainda que diversas políticas foram adotadas para tornar o sistema mais interligado, empresas manufatureiras chinesas ainda possuem um nível baixo de capacidade tecnológica. Nesse sentido, a colaboração com as universidades e as instituições públicas de pesquisa, que possuem um nível alto de tecnologia, é um modo eficaz de se atingir capacidades competitivas de inovação (MOTOHASHI; YUN, 2007).

Entretanto, o nível de colaboração na China ainda é menor do que nos países desenvolvidos. Por exemplo, mais da metade das empresas de P\&D japonesas estão conduzindo projetos de pesquisa conjuntos com universidades. A capacidade tecnológica relativa das empresas, comparada com as instituições públicas de pesquisa e universidades é significativamente menor na China do que no Japão. Com exceção das empresas de ponta, a maior parte das empresas chinesas não tem capacidade de inovação (MOTOHASHI; YUN, 2007).

\subsection{Universidades}

A instituição de ensino superior mais antiga da China, shuyuan (academia de ensino de Chinês clássico), teve início durante a Dinastia Tang (618-907), no século VIII. Esse modelo de instituição de ensino perdurou até o final da Dinastia Qing (16441911). Contudo, a primeira instituição de ensino superior equivalente a uma universidade ocidental foi estabelecida em 1895, e se chamava Beiyang gongxue, depois se tornando Tianjin University. Na sequência, Nanyan gongxue (Jiaotong University) e a Imperial University (Peking University) foram fundadas em 1896 e 1898. 
O ensino superior chinês foi sucessivamente influenciado por diversas ideias ocidentais. Primeiramente, o modelo japonês foi aplicado em 1902 e 1903, refletindo as tradições francesa e alemã. Depois do fim do império chinês, em 1911, as influências norte-americanas tomaram lugar de destaque em 1922 e 1924. Em 1932, o governo chinês convidou consultores europeus para a formulação de um projeto de reforma do ensino superior. Esta reforma tornou o Sistema de ensino superior mais centralizado e padronizado (HAYHOE, 1999).

A reestruturação do ensino superior depois do estabelecimento da República Popular da China em 1949 foi influenciada pelo modelo soviético, caracterizado pelo modelo de planejamento centralizado, com o governo alocando recursos, selecionando líderes e decidindo número de vagas por instituição (CAI, 2014).

Desde o final dos anos 1970, o país lançou contínuas reformas junto com a introdução da política de abertura, especialmente na área econômica. A fim de atingir os requisites dessa reestruturação econômica, a China iniciou uma série de reformas do ensino superior, especialmente a partir de 1993. Duas estratégias de reforma foram colocadas em uso: introduzir forças de mercado para liberalizar a educação, criar ímpeto para mudança, encorajar a competição; e usar a legislação para regular novas relações sociais, práticas e comportamentos que surgirem da primeira estratégia (LAW, 2002).

As reformas tiveram sucesso, como a expansão em escala do ensino superior, diversificação do financiamento, desenvolvimento de universidades competitivas, e o avanço na internacionalização do ensino superior (WANG; LIU, 2009).

O sistema de ensino superior da China é dividido em quatro categorias: instituições de pesquisa; instituições de ensino e pesquisa; instituições de ensino; e instituições orientadas à aplicação. As universidades de pesquisa são as 112 instituições do Projeto 211, que é um programa do governo iniciado em 1993 com objetivo de fortalecer cerca de 100 IES como prioridade nacional para o século 21. Dentre elas, 39 instituições foram selecionadas para serem as universidades do Projeto 985. Este projeto foi criado pelo governo chinês a fim de promover universidades de padrão internacional.

Enquanto a China manteve um rápido crescimento econômico nas últimas três décadas, a mão-de-obra barata e a manufatura intensiva como motor do crescimento econômico foi suplantado por competidores emergentes do sudeste asiático e levou à 
degradação do meio ambiente na China. Para garantir um desenvolvimento sustentável no futuro, o país mudou sua prioridade econômica de produção de trabalho intensivo para produção de capital e tecnologia intensivos. Desde a virada do milênio a China vem aumentando o investimento em ciência e tecnologia, e também caminhando para a construção de um sistema de inovação de alta performance e economia do conhecimento.

Essas mudanças econômicas levantaram duas demandas para o ensino superior: o desenvolvimento de recursos humanos e o engajamento do ensino superior no desenvolvimento econômico.

Primeiramente, para desenvolver uma economia do conhecimento, o país precisa melhorar a qualidade dos seus recursos humanos. Para isso é necessário que as universidades melhores a qualidade da educação e ajuste as estruturas dos programas a fim de suprir as demandas da construção econômica. Há também demandas para diferentes tipos de especialidades, para as várias necessidades de desenvolvimento econômico.

A transformação econômica em direção a um sistema de inovação colocou as universidades em uma posição central. Além de ensino e pesquisa, é esperado das universidades engajar mais com a sociedade, principalmente o setor industrial.

As universidades têm impacto substancial no desenvolvimento econômico regional, com efeitos de curto ao longo prazo. No curto prazo, os efeitos estão relacionados com o emprego de trabalhadores locais nas universidades, a ocupação de uma grande porção de terra e a demanda por serviços locais. Ao longo prazo os efeitos no desenvolvimento econômico regional podem ser observados: a universidade vai melhorar a qualidade da mão-de-obra a partir de graduados treinados; a existência de uma universidade na região age como um incentivo para empresas locais expandir suas atividades a fim de tirar vantagem da mão-de-obra qualificada; uma equipe bem qualificada da universidade pode prover consultoria para agências e empresas locais; a presença de uma universidade aumenta a atratividade econômica para empresas e profissionais bem qualificados.

Na China as regiões a nível provincial se tornaram a unidade básica para os sistemas de inovação em desenvolvimento. Essas regiões estão sob o controle do 
governo central, mas também possuem um alto grau de autonomia administrativa e econômica.

As instituições de ensino superior chinesas são administradas pelo governo central ou pelos governos locais, provinciais ou municipais. No primeiro nível, as instituições são conhecidas como universidades nacionais, geralmente mais voltadas à ciência, servindo às prioridades nacionais e educando a elite, enquanto que as outras são universidades regionais, com a finalidade de massificar o ensino superior e servir a interesses regionais (CAI, 2011). Para distinguir melhor as jurisdições, as universidades nacionais frequentemente estão engajadas no desenvolvimento local das regiões onde se encontram. Muitas universidades nacionais estão sob o governo central e local por meio de uma jurisdição conjunta, onde os dois governos cooperam assim como foi acordado bilateralmente.

Geralmente as instituições de ensino superior da China numa província, independentemente da sua jurisdição, recrutam mais estudantes locais do que estudantes de outras regiões. Isso porque o exame nacional de ingresso no ensino superior, o gaokao, tem o número de vagas para estudantes locais e estudantes externos estabelecidos previamente de acordo com a capacidade das instituições da região.

Em termos do papel que as universidades têm no desenvolvimento econômico regional, um dos problemas é que pouca atenção é dada para as necessidades variadas do mercado de trabalho.

Apesar da tentativa de quase todas instituições de ensino superior de se tornarem mais orientadas à pesquisa e mudar seu status no sistema educacional, apenas 39 universidades do Projeto 985 estão categorizadas como universidades de pesquisa. Há críticas que o ensino superior chinês nem fornece pessoal científico e técnico para as empresas a fim de promover inovação tecnológica, nem provê mão-de-obra capacitada para o desenvolvimento de diferentes setores econômicos.

Enquanto que sistemas de inovação em desenvolvimento prezam por ligações diretas entre universidades e empresas, outro problema enfrentado pela China são as ligações fracas entre os dois setores, principalmente no que diz respeito à transferência de tecnologia. 
A maior parte das universidades têm baixa propensão a se engajar diretamente nas atividades econômicas, tendo em vista que há deficiências dos direitos à propriedade intelectual e na legislação contratual (KROLL; LIEFNER, 2008). Com isso, as empresas normalmente demandam apenas alguns serviços das universidades, ligados a cooperação a curto prazo para solução de problemas técnicos que surgem durante a produção. Como resultado, há uma falta de confiança e motivação entre universidade e indústria para desenvolver um relacionamento efetivo e recíproco na China (KROLL; LIEFNER, 2008).

Apesar dos desafios mencionados, a nível regional, as interações entre universidade e indústria ocorrem de três formas: por meio de empresas universitárias; nos parques tecnológicos de universidades; em cidades universitárias.

Em 1992 o governo lançou um projeto promovendo a cooperação entre empresas, universidades e institutos de pesquisa. Com isso, diversas universidades tiveram a iniciativa de estabelecer suas empresas, integrando vários estágios de pesquisa, desenvolvimento e processo de comercialização em uma só entidade, evitando processos de negociação com outras empresas (KROLL; LIEFNER, 2008).

Desde a virada do milênio, o número de empresas universitárias caiu, enquanto outras formas de relações universidade-indústria se tornaram mais populares, como a pesquisa colaborativa entre universidades e empresas, educação e treinamento, transferência de tecnologia e parques científicos universitários (EUN, 2009).

As universidades chinesas estão mais engajadas com o setor industrial através de parques industriais, e mais recentemente com parques científicos universitários inspirados no Stanford Science Park, por exemplo. Desde que o governo chinês aprovou o Peking University Science Park em 1999, um total de 86 parques científicos foram estabelecidos na China. O contexto apresentado representa o cenário geral do país. Como a China é diversa, situações específicas variam de acordo com as regiões, dependendo das condições do desenvolvimento econômico local. 


\section{MÉTODOS e DADOS}

\subsection{Metodologia}

Foram utilizadas na pesquisa metodologias mistas (qualitativa e quantitativa), a fim de aprofundar a investigação sobre as relações das IES com o sistema nacional de inovação chinês. As técnicas de pesquisa utilizadas foram a análise quantitativa multivariada de dados (regressão) e estudos de caso. Ambas técnicas foram utilizadas conjuntamente para garantir uma melhor abordagem do objeto, a fim de tentar reduzir as deficiências causadas pelas lacunas teóricas e de dados que o tema dos sistemas nacionais de inovação, seus atores e relações, contém.

Os procedimentos foram realizados em paralelo para que tanto a literatura contribuísse à seleção das variáveis (número de graduados, patentes, investimentos, internacionalização, etc), quanto a análise dos dados contribua para o melhor entendimento do caso, assim como proposto por Seawright (2016) com a abordagem Multi-Methods, integração de métodos quantitativos e qualitativos (regressão e estudo de caso).

\subsection{Banco de Dados e Variáveis}

Foi construído um banco de dados, em modo painel, a partir de dados já existentes, a princípio exclusivamente retirados do National Bureau Statistic of China, principal fonte estatística utilizada pela literatura que trata sobre dados da China (ZHANG, 2011; HU; MATHEWS, 2008; EUN; LEE; WU, 2006). Nele estão contidas diversas variáveis, cujas mais importantes serão apresentadas abaixo, referentes às 31 províncias da China, e contendo dados dos anos de 2006 até 2017. Tanto o banco de dados quanto as análises foram feitos utilizando o software Stata 13.

Para a análise quantitativa foram utilizados modelos de análise de dados apropriados para se verificar e mensurar a existência de relações entre os indicadores de inovação e de características das instituições de ensino superior. Alguns modelos já desenvolvidos por Hu e Mathews (2008), Fagerberg e Srholec (2008), Andersson et al. (2009), Cheung e Lin (2004), Zhang (2011), foram utilizados como alicerces na escolha das variáveis e modelo teórico que irão guiar a busca dos dados.

Variáveis como número de patentes, gastos com P\&D e C\&T (SMITH, 2005; OCDE, 1997), indicadores de características das IES (número de graduados, razão entre 
número de professores e alunos, número de instituições) (ZHANG, 2011; FAGERBERG; SRHOLEC; VERSPAGEN, 2010; ANDERSSON et al., 2009; ACS et al. 2002; HU; MATHEWS, 2008; FAGERBERG; SRHOLEC, 2008), número de empresa estrangeiras, exportação e importação, PIB e população (CHENG; LIN, 2004; HU; MATHEWS, 2008; FAGERBERG; SRHOLEC, 2008; FAGERBERG; SRHOLEC; VERSPAGEN, 2010) estão presentes no banco de dados e foram consideradas nas análises preliminares, a fim de verificar como e em que medida ocorre a participação das IES no sistema de inovação da China. É importante ressaltar as limitações de se utilizar as patentes como indicador de inovação, já que muitas inovações organizacionais, por exemplo, não são patenteáveis (OCDE, 1997; SMITH, 2005; FAGERBERG; SRHOLEC; VERSPAGEN, 2010). Entretanto, o indicador é amplamente utilizado na literatura tendo em vista a ausência de outros indicadores de maior relevância.

Contando com 372 observações, divididas por 31 províncias em 12 anos, a variável que mede os outputs de inovação [patents] é apresentada por unidades de patentes cujo registro foi aceito. As variáveis utilizadas como indicadores de educação [ngraduates] e [stratio] representam, respectivamente, o número de graduados (em dezenas de milhares de habitantes), e a razão entre o número de alunos e professores. As variáveis [operatexp] e [operatimp], utilizadas como indicadores de abertura internacional se referem à exportação e importação das empresas locais em operação. A variável [rdexpenditure] os gastos com P\&D das empresas locais, em dezenas de milhares de yuan, enquanto que a variável $[G R P]$ mede o Produto Regional Bruto, em 100 milhões de yuan, moeda chinesa. As demais variáveis do banco estão contidas no Apêndice.

\subsection{Resultados}

O valor médio de patentes foi de $30464,75 \pm 51539$. Já o gasto com $R \& D$ foi de $2528515 \pm 3533076$. O número de graduados foi de $19,07 \pm 12,81$. A razão média entre professores e alunos foi de 17,33 $\pm 1,08$. O valor médio do produto regional bruto foi de $17244,36 \pm 15692$. O gasto do governo com ciência e tecnologia foi de $76,93 \pm 101,5$. A média da exportação das unidades operacionais foi de $5,79 \times 10^{7} \pm 1,10 \times 10^{8}$ e a de importação foi de $4,80 \times 10^{7} \pm 8,66 \times 10^{7}$ (Tabela 1 ). 
Tabela 1 - Estatísticas descritivas das variáveis utilizadas no modelo

\begin{tabular}{r|rrrrr} 
Variable & Obs & Mean & Std. Dev. & Min & Max \\
\hline patents & 372 & 30464.75 & 51539.86 & 68 & 332652 \\
rdexpendit re & 279 & 2528515 & 3533076 & 1637 & $1.87 e+07$ \\
ngraduates & 372 & 19.0743 & 12.81489 & .38 & 57.12 \\
stratio & 372 & 17.33578 & 1.07904 & 13.48 & 19.37 \\
grp & 372 & 17244.36 & 15692 & 290.76 & 89705.23 \\
\hline govexpst & 341 & 76.93026 & 101.496 & 1.93 & 823.89 \\
operatexp & 372 & $5.79 e+07$ & $1.10 e+08$ & 222218 & $6.46 e+08$ \\
operatimp & 372 & $4.80 e+07$ & $8.66 e+07$ & 26630 & $4.55 e+08$
\end{tabular}

De acordo com a análise multivariada de dados (Tabela 2), foi possível observar a associação entre o número de patentes [patents], com a razão entre número de professores e alunos [stratio], os gastos do governo com C\&T [govexpst] e indicadores de exportação [operatexp].

As variáveis de gastos do governo com C\&T e exportação [govexpst] e [operatexp] apresentaram coeficientes de associação positivos (180.3189 e 0.0003, respectivamente) com o número de patentes. Enquanto que a variável da razão entre número de professores e alunos apresentou coeficiente de associação negativo (5421.194).

Tabela 2. Regressão xtreg efeitos aleatórios

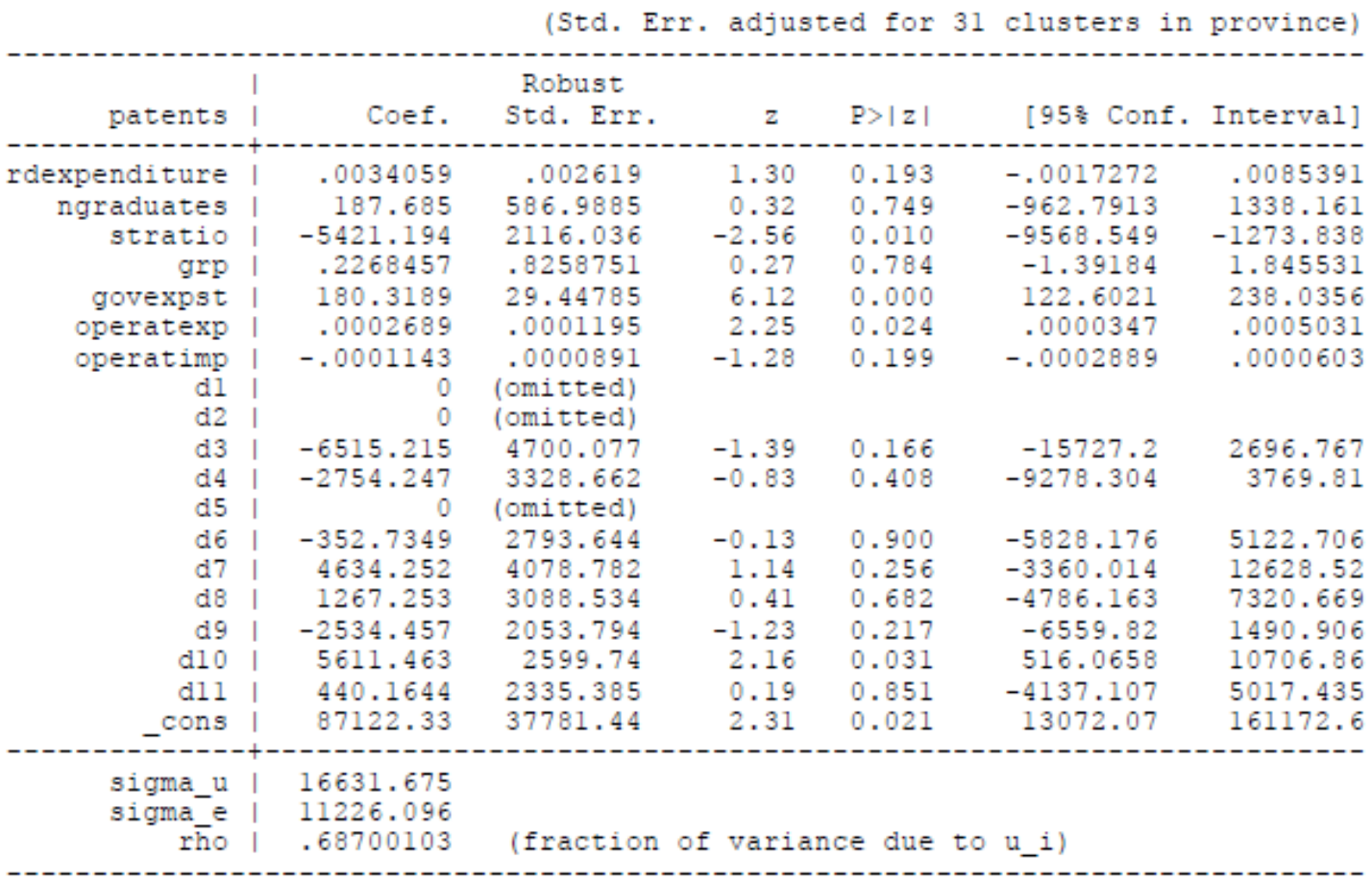


Foram realizados diversos testes para verificação da robustez do modelo, que estão presentes no Apêndice.

\section{DISCUSSÃO}

Este trabalho avaliou a associação entre o número de patentes com os indicadores de ensino superior na China em um modelo de analise multivariada.

As variáveis de gastos do governo com C\&T e exportação govexpst e operatexp apresentaram coeficientes de associação positivos (180.3189 e 0.0003, respectivamente) com o número de patentes. Enquanto que a variável da razão entre número de professores e alunos apresentou coeficiente de associação negativo (-5421.194). Quanto maior o número de professores e alunos menor o número de patentes.

O principal indicador de participação das instituições de ensino superior, medido pelo número de graduados [ngraduates] não apresentou relação com a variável de patentes, enquanto que a variável [stratio] apresentou relação negativa com o número de patentes. Isso demonstra que a qualidade da educação superior, medida pela razão estudantes-professores, têm impacto no número de patentes, enquanto que a variável número de graduados, medindo a quantidade de alunos, não possui impacto.

Quanto mais estudantes por professor, menor o número de patentes, sinalizando a importância da qualidade do oferecimento de ensino superior, mais do que o número de graduados. Assim, observamos que as medidas adotadas pelo governo chinês no sentido de promover a melhora na qualidade da educação, após a sua expansão quantitativa através da massificação do ensino superior podem surtir efeito nos indicadores de inovação, como planejado. 


\section{REFERÊNCIAS BIBLIOGRÁFICAS}

ACS, Z.; ANSELIN, L.; VARGA, A. Patents and innovation counts as measures of regional production of new knowledge. In: Research Policy. N. 31 V. 7, 2002.

ANDERSSON, Roland; QUIGLEY, John M.; WIHELMSSON, Mats. Urbanization, productivity, and Innovation: Evidence from investment in higher education. In: Journal of Urban Economics. Fev. 2009.

ARRIGHI, Giovanni. Adam Smith in Beijing: Lineages of the Twenty-First Century. London; New York: Verso, 2007.

ARRIGHI, Giovanni; ZHANG, Lu. Beyond the Washington Consensus: A New Bandung? In: SHEFNER, Jon; FERNÁNDEZ-KELLY, Patricia (ed.). Globalization and Beyond: New Examinations of Global Power and its Alternatives. Philadelphia: Penn State University Press, 2010.

BREZNITZ, Dan; MURPHEE, Michael. Run of the Red Queen: Government, Innovation, Globalization, and Economic Growth in China. New Haven: Yale University Press, 2011.

CAI, Y. Implementing the triple helix model in a non-western context: an institutional logics perspective. Research Open Access, 2014.

CAI, Y.; YAN, F. Demands and Responses in Chinese Higher Education. In: SCHWARTZMAN, S.; PINHEIRO, R.; PILLAY, P. (ed.) Higher Education in the BRICS Countries: Investigating the Pact Between Higher Education and Society. New York: Springer, 2015. Série Higher Education Dynamics

CHANG, Ha-Joon. Chutando a Escada: A estratégia de desenvolvimento em perspectiva histórica. São Paulo: Editora UNESP, [2003], 2002.

CHEN, K.; KENNEY, M. Universities/Research Institutes and Regional Innovation Systems: the cases of Beijing and Shenzhen. World Development v. 35, n. 6, pp. 10561074, 2007.

CHEUNG, Kui-yin; LIN, Ping. Spillover effects of FDI on innovation in China: Evidence from the provincial data. In: China Economic Review. N. 15, 2004.

CHI, Fulin. Choice of reform options in line with trends of economic transformation in the 13th Five-year Plan period. 2015. Disponível em: <http://www.chinareform.org/ publications/reports/201511/t20151102_237488.htm> Acesso em: 20 jul 2017

EDQUIST, Charles. Systems of Innovation: Perspectives and Challenges. In: FAGERBERG, Jan.; MOWERY, David C.; NELSON, Richard R. (ed.) The Oxford Handbook of Innovation. New York: Oxford University Press, 2005.

ETZKOWITZ, Henry; LEYDESDORFF, Loet. The dynamics of innovation: from National Systems and "Mode 2" to a Triple Helix of university-industry-government relations. In: Research Policy. N. 29, 2000.

FAGERBERG, Jan. Innovation: A Guide to the Literature. In: FAGERBERG, Jan.; MOWERY, David C.; NELSON, Richard R. (ed.) The Oxford Handbook of Innovation. New York: Oxford University Press, 2005. 
FAGERBERG, Jan; FOSAAS, Morten; SAPPRASERT, Koson. Innovation: Exploring the knowledge base. Research Policy, n. 41, 2012, p. 1132-1153

FAGERBERG, Jan; SRHOLEC, Martin. National innovation systems, capabilities and economic development. Research Policy, n. 37, 2008, p. 1417-1435.

FAGERBERG, Jan; SRHOLEC, Martin; VERSPAGEN, Bart. Innovation and Economic Development. In: ARROW, K.; INTRILIGATOR, M. (Ed.) Handbook of the Economics of Innovations. Amsterdam: Elsevier, 2010. Volume 2.

FAN, P. Innovation on China. Economic Surveys v. 28, n. 4, pp. 725-745, 2014.

FISCHER, M. M.; VARGA, A. Spatial knowledge spillovers and university research: evidence from Austria. In: Annals of Regional Science. N. 37, 2003.

FREEMAN, C. Technology Policy and Economic Performance: Lessons from Japan. London: Pinter, 1987.

FURTADO, Celso. Dialética do desenvolvimento. Rio de Janeiro: Fundo de Cultura, 1964.

GALLI, R.; TEUBAL, M. Paradigmatic shifts in National Innovation Systems. In: EDQUIST, C. (ed.) Systems of Innovation: Technologies, institutions and organizations. London: Pinter Publishers, 1997.

GAULT, Fred. Innovation indicators and measurement: challenges. In: Handbook of Innovation Indicators and Measurement. Cheltenham; Northhamptom: Edward Elgar Publishing, 2013.

GERSCHENKRON, A. Economic Backwardness in Historical Perspective. Cambridge: The Belknap Press, 1962.

GRILICHES, Z. R\&D, Patents and Productivity. Chicago: University of Chicago Press, 1984.

HAYHOE, R. China's Universities 1895-1995: A Century of Cultural Conflict (2nd ed.). Hong Kong: Comparative Education Research Centre, The University of Hong Kong, 1999.

JAFFE, A. Real effects of academic research. In: American Economic Review. n. 79, 1989.

KAO, John. Innovation Nation: How America is losing its innovation edge, why it matters, and what we can do to get it back. New York: Free Press, 2007.

KRÜCKEN, G. University Research and Innovation. In: CARAYANNIS, Elias G. (ed) Encyclopedia of Creativity, Invention, Innovation, and Entrepreneurship. New York: Springer, 2013.

LIU, X.; WHITE, S. Comparing innovation systems: a framework and application to China' transition context. Research Policy v. 30, pp. 1091-1114, 2001.

LIU, F.; SIMON, D. F.; SUN, Y.; CAO, C. China's innovation policies: evolution, institutional structure, and trajectory. Research Policy v. 40, pp. 917-931, 2011. 
LLERENA, Patrick; MATT, Mireille. Innovation Policy in a Knowledge-Based Economy: Theory and Practice. Berlin: Springer, 2005.

LUNDVALL, Bengt-Ake. (Ed.) National Systems of Innovation: Towards a Theory of Innovation and Interactive Learning. London: Anthem Press, [1992], 2010.

LUNDVALL, Bengt-Ake; BORRÁS, Susana. Science, Technology, and Innovation Policy. In: FAGERBERG, Jan.; MOWERY, David C.; NELSON, Richard R. (ed.) The Oxford Handbook of Innovation. New York: Oxford University Press, 2005.

MARX, Karl; ENGELS, Friedrich. Manifesto Comunista. São Paulo: Boitempo Editorial, 1998.

MATHEWS, John A.; HU, Mei-Chih. Universities and Public Research Institutions as Drivers of Economic Development in Asia. In: YUSUF, Shahid; NABESHIMA, Naoru. (ed.) How Universities Promote Economic Growth. Washington: The World Bank, 2007.

MEEUS, Marius; OERLEMANS, Leon. National innovation systems. In: CASPER, Steven; WAARDEN, Frans van. Innovation and Institutions: A multidisciplinary review of the study of Innovation Systems. Cheltenham; Northampton: Edward Elgar Publishing, 2005.

MOE, Ministry of Education. Outline of China's National Plan for Medium and Longterm Education Reform and Development. Ministry of Education of the People's Republic of China, 2010. Disponível em: <https://internationaleducation.gov.au/News/ newsarchive/2010/Documents/China_Education_Reform_pdf.pdf $>$. Acesso em: 15 jul. 2017.

MOK, K. H.; YUE, K. Promoting Entrepreneurship and Innovation in China: Transformations in University Curriculum and Research Capacity. In: SCHWARTZMAN, S.; PINHEIRO, R.; PILLAY, P. (ed.) Higher Education in the BRICS Countries: Investigating the Pact Between Higher Education and Society. New York: Springer, 2015. Série Higher Education Dynamics

MOST, Ministry of Science and Technology. National Outline for Medium and Long Term Science and Technology Development Planning (2006-2020). Ministry of Science and Technology of the People's Republic of China, 2006 Disponível em: <http://www.most.gov.cn/eng/newsletters/2006/200611/t20061110_37960.htm> Acesso em: 15 jul. 2017.

MOTOHASHI, K.; YUN, X. China's innovation system reform and growing industry and science linkages. Research Policy, 2007.

MOWERY, David C.; SAMPAT, Bhaven N. Universities in National Innovation Systems. In: FAGERBERG, Jan.; MOWERY, David C.; NELSON, Richard R. (ed.) The Oxford Handbook of Innovation. New York: Oxford University Press, 2005.

NATIONAL Bureau Statistics of China (NBS). National Data: banco de dados. Disponível em: <http://data.stats.gov.cn/english>. Acesso em: 06/jun/2018

NELSON, R. (Ed.). National innovation systems: a comparative analysis. New York, Oxford: Oxford University, 1993. 
NELSON, R.; ROSENBERG, N. Technical innovation and national systems. In: NELSON, R. (Ed.). National innovation systems: a comparative analysis. New York, Oxford: Oxford University, 1993. p. 3-21.

NPC. China's NPC Approves 13th Five-Year Plan. National People's Congress of China, 2016. Disponível em: <http://www.npc.gov.cn/npc/zgrdzz/site1/20160429/ 0021861abd66188d449902.pdf>. Acesso em: 18 jul. 2017.

NPC. Constitution of the People's Republic of China. National People's Congress of the People's Republic of China, 2004. Disponível em: <http://www.npc.gov.cn/englishnpc/ Constitution/2007-11/15/content_1372963.htm> Acesso em: 18 jul. 2017.

ORGANIZAÇÃO para a Cooperação e Desenvolvimento Econômico. Manual de Oslo: Diretrizes para coleta e interpretação de dados sobre inovação. Paris: OCDE, 1997.

PARK, E. Higher Education and Innovation. In: CARAYANNIS, Elias G. (ed) Encyclopedia of Creativity, Invention, Innovation, and Entrepreneurship. New York: Springer, 2013.

PAULINO, Luís Antonio. Apresentação. In: POSSAS, Lídia M. V.; SALA, José Blanes (Org). Novos atores e Relações Internacionais. Marília: Cultura Acadêmica, 2010.

PIRES, Marcos Cordeiro. A inserção de Brasil e China no processo de Globalização 1980 - 2002. In: POSSAS, Lídia M. V.; SALA, José Blanes (Org). Novos atores e Relações Internacionais. Marília: Cultura Acadêmica, 2010.

RAMO, Joshua Cooper. The Beijing Consensus. London: Foreign Policy Centre, 2004. Disponível em: <http://fpc.org.uk/fsblob/244.pdf> Acesso em: 18 jul. 2016.

SCHUMPETER, Joseph A. A Teoria do Desenvolvimento Econômico: Uma investigação sobre Lucros, Capital, Crédito, Juro e o Ciclo Econômico. São Paulo: Nova Cultural, [1912], 1997.

SCHUMPETER, Joseph A. Capitalismo, Socialismo e Democracia. Rio de Janeiro: Editora Fundo de Cultura, [1942], 1961.

SCHWAB, Klaus. The Fourth Industrial Revolution. Geneva: World Economic Forum, 2016.

SEAWRIGHT, Jason. Multi-Method Social Science: Combining Qualitative and Quantitative Tools. Cambridge University Press: Cambridge, 2016.

SMITH, Keith. Measuring Innovation. In: FAGERBERG, Jan.; MOWERY, David C.; NELSON, Richard R. (ed.) The Oxford Handbook of Innovation. New York: Oxford University Press, 2005.

SOETE, Luc; VERSPAGEN, Bart; WEEL, Bas Ter. Systems of Innovation. In: ARROW, K.; INTRILIGATOR, M. (Ed.) Handbook of the Economics of Innovations. Amsterdam: Elsevier, 2010. Volume 2.

SOLOW, R. A Contribution to the Theory of Economic Growth. In: The Quarterly Journal of Economics, Vol 70, n. 1, fev. 1956. 
SONG, Hefa. China's National Innovation System. In: CARAYANNIS, Elias G. (ed) Encyclopedia of Creativity, Invention, Innovation, and Entrepreneurship. New York: Springer, 2013.

VARGA, A. Local academic knowledge transfers and the concentration of economic activity. In: Journal of Regional Science. n. 40, v. 2, 2000.

VARGA, A. University Research and Regional Innovation. Boston: Kluwer Academic Publishers, 1998.

VERSPAGEN, Bart. Innovation and Economic Growth. In: FAGERBERG, Jan.; MOWERY, David C.; NELSON, Richard R. (ed.) The Oxford Handbook of Innovation. New York: Oxford University Press, 2005.

WOOLDRIDGE, Jeffrey M. Introductory Econometrics: A modern approach. SouthWestern College Pub., 2012

WU, Weiping. Building Research Universities for Knowledge Transfer: The case of China. In: YUSUF, Shahid; NABESHIMA, Naoru. (ed.) How Universities Promote Economic Growth. Washington: The World Bank, 2007.

XUE, L. A historical perspective of China's innovations system reform: a case study. Journal of Engineering and Tchnology Management, 1997.

YUSUF, Shahid. University-Industry Links: Policy Dimensions. In: YUSUF, Shahid; NABESHIMA, Naoru. (ed.) How Universities Promote Economic Growth. Washington: The World Bank, 2007.

ZENG, Ming; WILliAMSON, Peter J. Dragons at your door: How Chinese Cost Innovation is Disrupting Global Competition. Boston: Harvard Business School Press, 2007.

ZHA, Q.; HAYHOE, R. The Chinese Model of Development and the Higher Eduction Policy. In: SCHWARTZMAN, S.; PINHEIRO, R.; PILLAY, P. (ed.) Higher Education in the BRICS Countries: Investigating the Pact Between Higher Education and Society. New York: Springer, 2015. Série Higher Education Dynamics

ZHANG, Chunlin; ZENG, Douglas Zhihua; MAKO, William Peter; SEWARD, James. Promoting Enterprise-Led Innovation in China. Washington: The World Bank, 2009.

ZHANG, Xin. Patent development, $R \& D$ intensity and human capital: a study based on a panel data model. Tese de Bacharelado, School of Business and Economics Linnaeus University, 2011. 


\section{APÊNDICE}

\section{Variáveis do banco de dados}

province - Nome das províncias

year-Ano

patents - Número total de patentes aprovadas

design - Número de patentes de design aprovadas

utilitymodels - Número de patentes de utilidade aprovadas

invention - Número de patentes de invenção aprovadas

rdexpenditure - Gastos com P\&D das Empresas Industriais (10000 yuan)

ftrdpersonnel - Funcionários de P\&D das Empresas Industriais

rdprojects - Número de projetos de P\&D das Empresas Industriais (item)

nrinstitutions - Número de Instituições de Ensino Superior (unidade)

nnstudents - Número de Novos Estudantes matriculados em Instituições de Ensino (10000)

nenrollment - Número de estudantes matriculados em Instituições de Ensino Superior (10000)

ngraduates - Número de Graduados em Instituição de Ensino Superior

nstudents - Número de Estudantes por 100000 pessoas no Ensino Superior (pessoa)

stratio - Razão entre número de Estudantes-Professor em Instituições de Ensino Superior

teachersstaff - Número de Professores e Funcionários em Instituições de Ensino Superior

ftteachers - Número de Professores com dedicação exclusive em Instituições de Ensino Supeiror (10000

p)

GRP - Produto Regional Bruto (100 milhões de yuan)

PCGRP - Produto Regional Bruto per capita (yuan/pessoa)

govexpedu - Gasto do Governo Local, Educação (100 milhões de yuan)

govexpst - Gasto do Governo Local, Ciência e Tecnologia (100 milhões de yuan)

govbudget - Gasto Orçamentário do Governo Local (100 milhões de yuan)

numforenterp - Número de Empresas Estrangeiras (unidade) 
population - População Residente (ano) (10000 pessoas)

edufunds - Fundos Educacionais (10000 yuan)

goveduapp - Apropriação do governo para educação

forenterinvest - Investimento total das empresas estrangeiras (USD milhão)

forenterexpimp - Valor Total de Importações e Exportações de Empresas Estrangeiras (1.000 US dólares)

forenterexp - Valor Total de Exportações de Empresas Estrangeiras (1.000 US dólares)

forenterimp - Valor Total de Importações de Empresas Estrangeiras (1.000 US dólares)

operatexpimp - Valor Total de Importações e Exportações de unidades operacionais (1.000 US dólares)

operatexp - Valor Total de Exportação das unidades operacionais (1.000 US dólares)

operatimp - Valor Total de Importação das unidades operacionais (1.000 US dólares)

fixedassetss - Investimento total em ativos permanentes no país, Orçamento do Governo (100 milhões yuan)

fixedassetsfi - Investimento total em ativos permanentes no país, Investimento estrangeiro (100 milhões yuan)

fixedassetstotal - Investimento total em ativos permanentes no país, subtotal dos fundos do ano (100 milhões yuan)

urbunemployment - Número de desempregados na área Urbana (10000 pessoas)

unemploymentrt - Taxa de Desemprego na área Urbana(\%) 
Estatísticas Descritivas

\begin{tabular}{|c|c|c|c|c|c|}
\hline Variable & $\mathrm{Obs}$ & Mean & Std. Dev. & Min & Man \\
\hline provincename & 0 & & & & \\
\hline year & 372 & 2011.5 & 3.456702 & 2006 & 2017 \\
\hline patents & 372 & 30464.75 & 51539.86 & 68 & 332652 \\
\hline design & 372 & 10072.26 & 22588.07 & 22 & 175758 \\
\hline utilitymod $\sim$ & 372 & 16000.16 & 24881.4 & 15 & 169017 \\
\hline invention & 372 & 4392.331 & 7547.795 & 4 & 46091 \\
\hline rdexpendit $\sim e$ & 279 & 2528515 & 3533076 & 1637 & $1.87 e+07$ \\
\hline ftrdperson $\sim 1$ & 279 & 71952.01 & 98420.95 & 22 & 457342 \\
\hline rdprojects & 279 & 9457.072 & 13142.15 & 14 & 73439 \\
\hline nrinstitut $\sim$ & 372 & 76.23387 & 38.41168 & 6 & 167 \\
\hline nnstudents & 372 & 21.66763 & 13.63732 & .8 & 56.94 \\
\hline nenrollment & 372 & 74.76231 & 47.63391 & 2.33 & 201.53 \\
\hline ngraduates & 372 & 19.0743 & 12.81489 & .38 & 57.12 \\
\hline nstudents & 310 & 2424.568 & 926.6655 & 165 & 6750 \\
\hline stratio & 372 & 17.33578 & 1.07904 & 13.48 & 19.37 \\
\hline teachersst $\sim f$ & 372 & 7.116801 & 4.197421 & .27 & 16.86 \\
\hline Etteachers & 372 & 4.514005 & 2.706523 & .17 & 11.29 \\
\hline$g r p$ & 372 & 17244.36 & 15692 & 290.76 & 89705.23 \\
\hline $\mathrm{p} \in g \mathrm{r}$ & 344 & 38465.91 & 23046.7 & 5750 & 128994 \\
\hline govexpedu & 341 & 573.0511 & 419.4676 & 33.57 & 2575.52 \\
\hline goverpst & 341 & 76.93026 & 101.496 & 1.93 & 823.89 \\
\hline govbudget & 372 & 3187.476 & 2297.127 & 174.54 & 15037.48 \\
\hline numforenterp & 372 & 13889.09 & 21312.48 & 115 & 135869 \\
\hline population & 372 & 4238.769 & 2751.995 & 285 & 11169 \\
\hline
\end{tabular}

\begin{tabular}{|c|c|c|c|c|c|}
\hline edufunds & 310 & 6815544 & 5317281 & 78582 & $3.37 e+07$ \\
\hline $\begin{array}{r}\text { goveduapp } \\
\text { forenterin } \sim \text { t }\end{array}$ & $\begin{array}{l}310 \\
372\end{array}$ & $\begin{array}{r}5627854 \\
109794.2\end{array}$ & $\begin{array}{r}6374612 \\
181767.3\end{array}$ & $\begin{array}{r}263422 \\
400\end{array}$ & $\begin{array}{r}9.06 e+07 \\
1762227\end{array}$ \\
\hline forentere mp & 371 & $5.27 e+07$ & 1. $09 e+08$ & 92 & $5.92 e+08$ \\
\hline forenterexp & 371 & $2.86 e+07$ & $6.25 e+07$ & 0 & $3.57 e+08$ \\
\hline forenterimp & 371 & $2.40 e+07$ & 4. $75 e+07$ & 0 & $2.35 e+08$ \\
\hline operatexpimp & 372 & $1.06 e+08$ & $1.89 e+08$ & 328377 & $1.09 e+09$ \\
\hline operaterp & 372 & $5.79 e+07$ & $1.10 e+08$ & 222218 & $6.46 e+08$ \\
\hline operatimp & 372 & $4.80 e+07$ & 8. $66 e+07$ & 26630 & $4.55 e+08$ \\
\hline fixedasset $\sim b$ & 372 & 606.8385 & 505.7289 & 22.79 & 2736.25 \\
\hline fixedasset i & 369 & 133.3957 & 222.5105 & 0 & 1404.15 \\
\hline fixedasset $\sim 1$ & 372 & 12330.01 & 10898.71 & 243.68 & 57282.81 \\
\hline urbunemplo t & 369 & 24.60626 & 13.98891 & 1.04 & 60.74 \\
\hline unemployme $\sim t$ & 369 & 3.476965 & .6577593 & 1.2 & 5.1 \\
\hline province & 372 & 16 & 8.956318 & 1 & 31 \\
\hline grpgrowth & 341 & 13.12841 & 7.159147 & -22.40085 & 32.27404 \\
\hline
\end{tabular}




\section{Testes}

Primeiramente foi rodado o modelo com efeitos fixos.

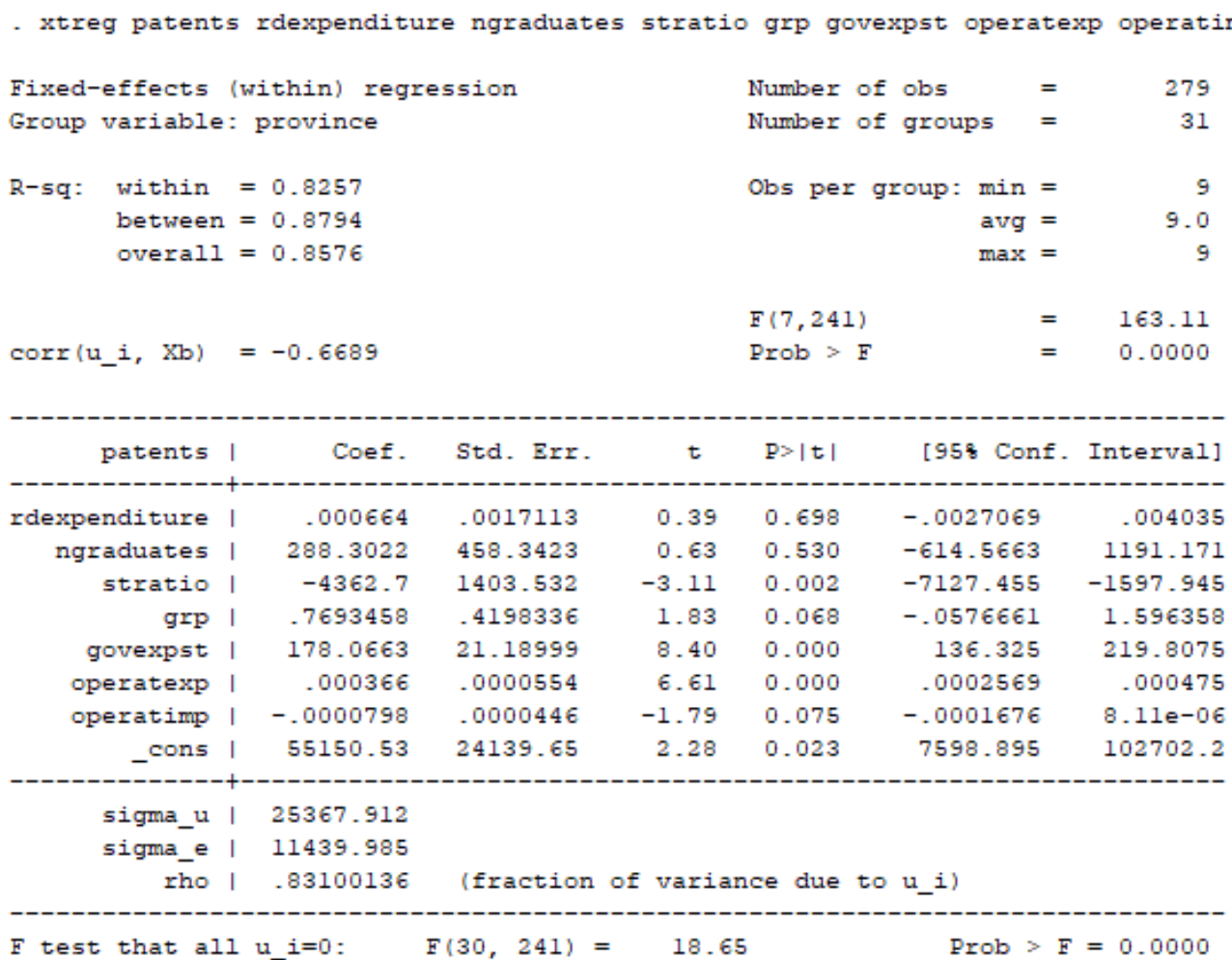

Em seguida, o mesmo modelo, mas com efeitos aleatórios.

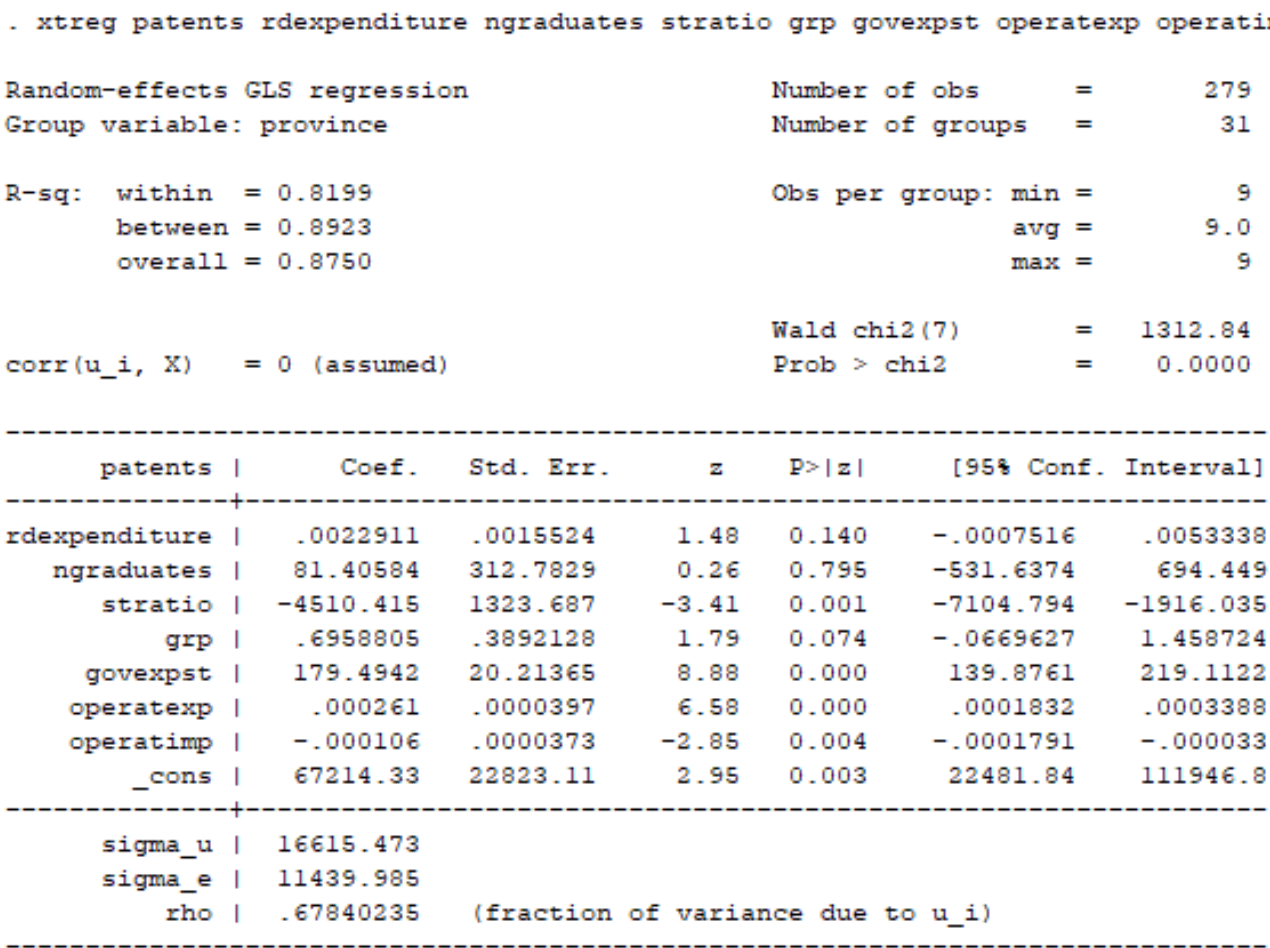


A fim de decidir qual melhor modelo de estimação (efeitos fixos ou aleatórios), foi rodado o Teste de Hausman, que indicou como melhor o modelo aleatório.

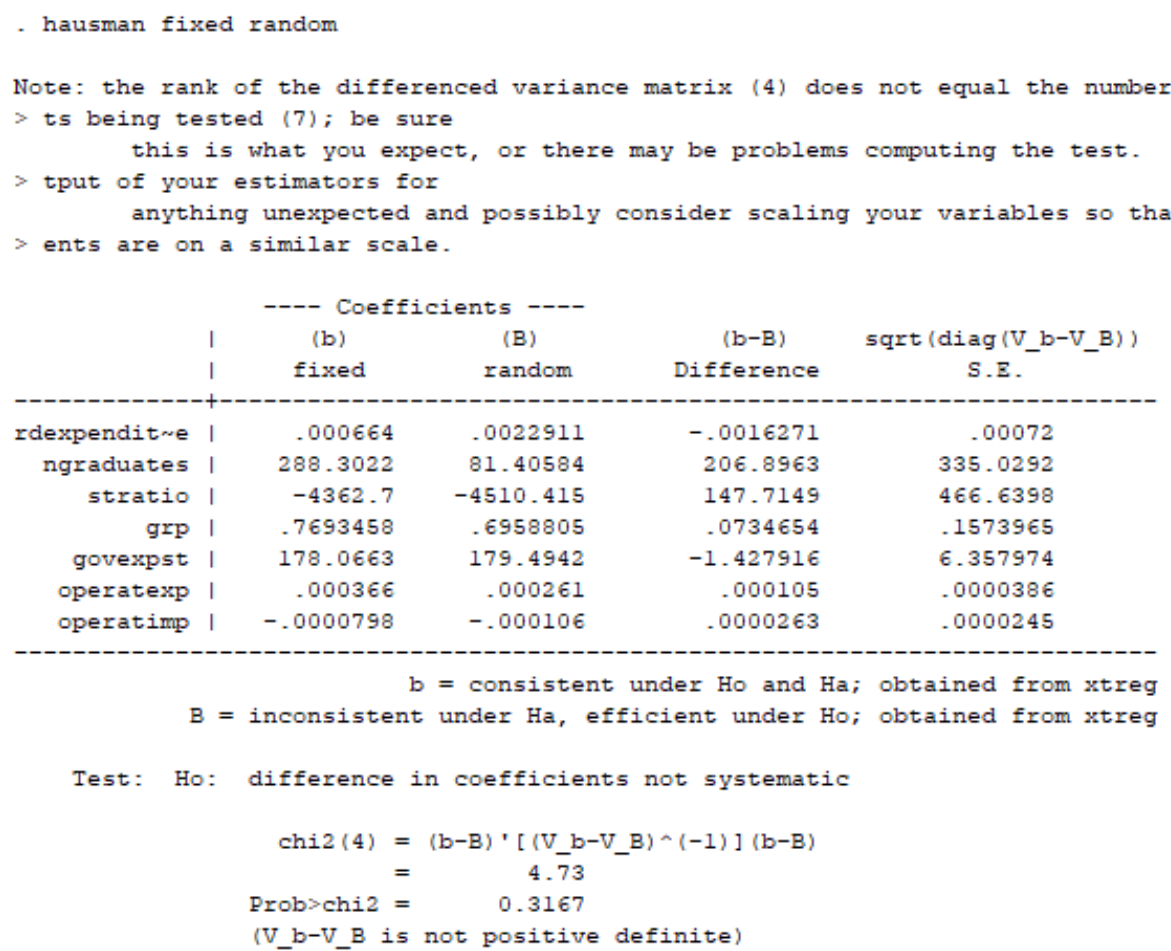

Foram então adicionadas as dummies por ano. 


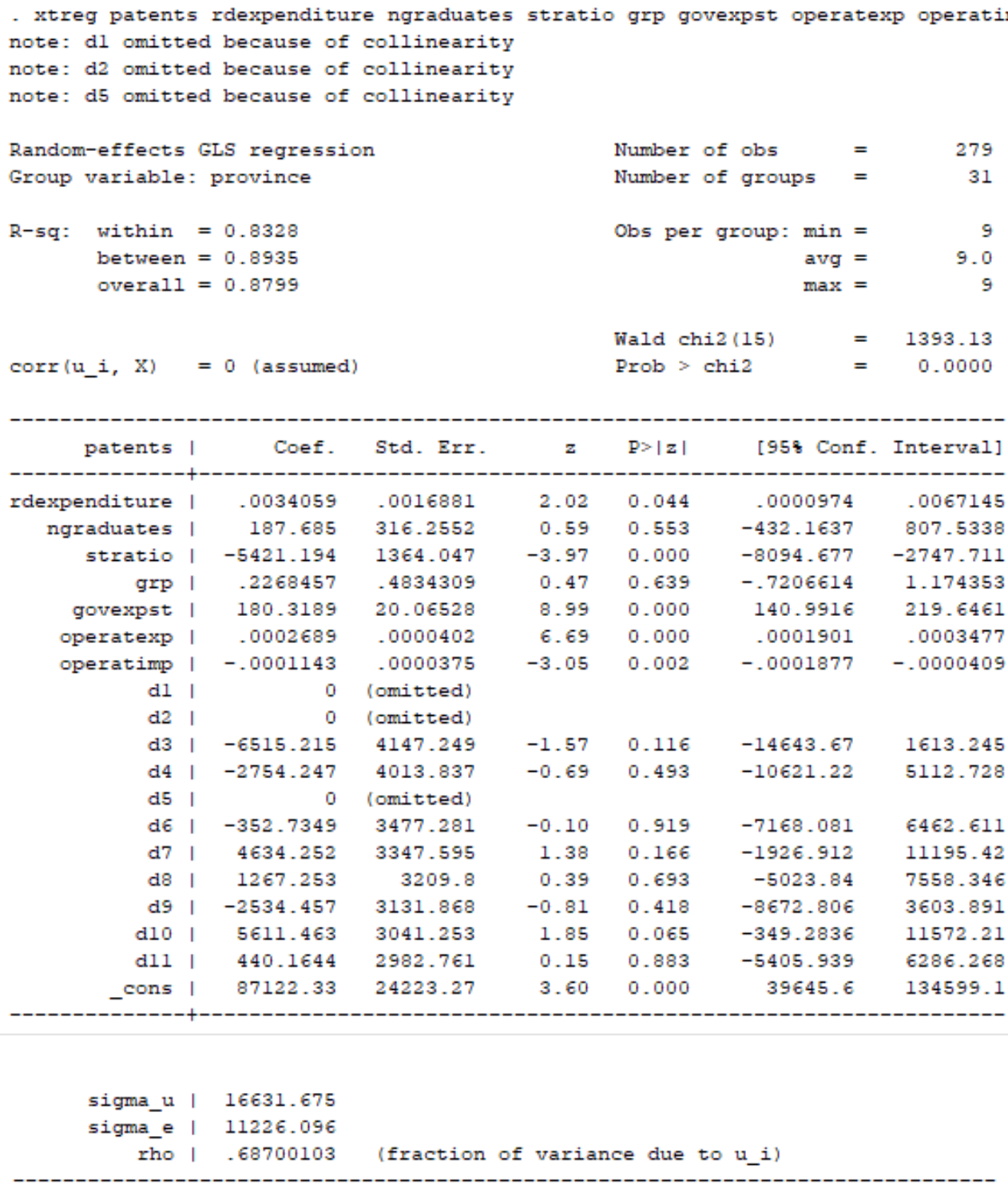

Foi rodado o Teste de Parm para verificar se efeitos fixos de tempo são necessários.

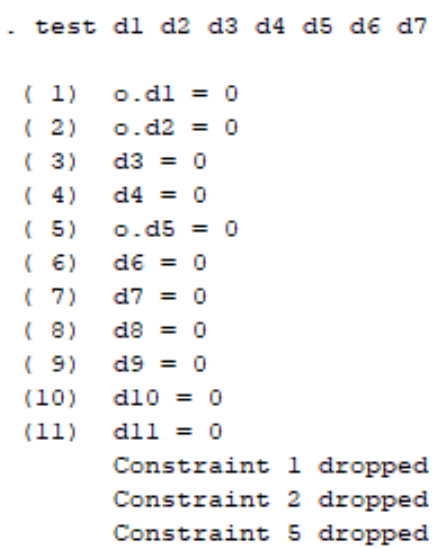

$$
\begin{aligned}
\operatorname{chi} 2(8) & =20.87 \\
\text { Prob }>\text { chi2 } & =0.0075
\end{aligned}
$$


Foi rodado o teste de Breusch e Pagan Lagrangian para decidir se é melhor uma regressão OLS ou uma regressão com efeitos aleatórios, que indicou o modelo de efeitos aleatórios como o mais apropriado.

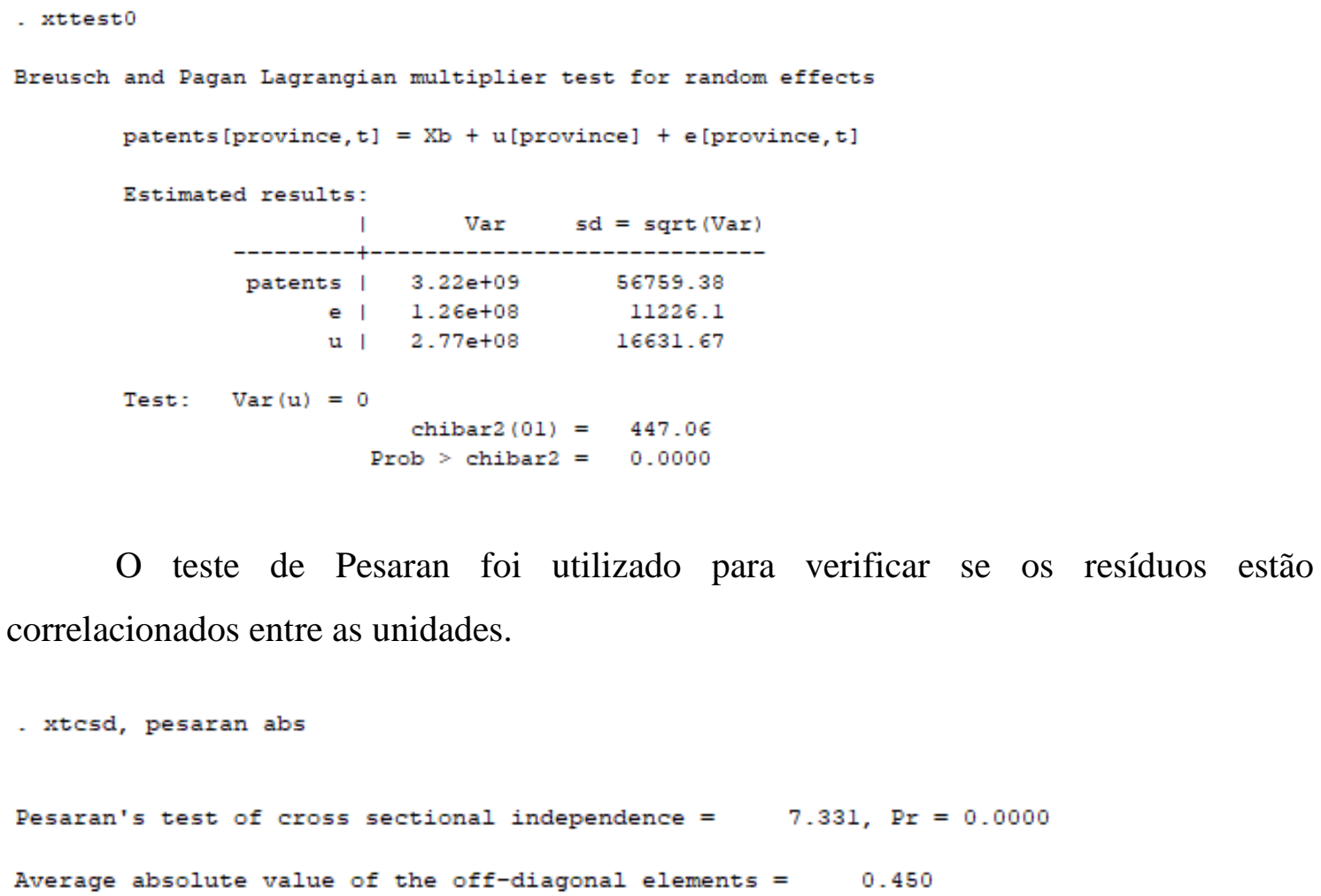

O teste de Pesaran foi utilizado para verificar se os resíduos estão correlacionados entre as unidades.

A partir desses testes foi escolhido o modelo final de efeitos aleatórios, com as dummies por ano, como apresentado abaixo: 


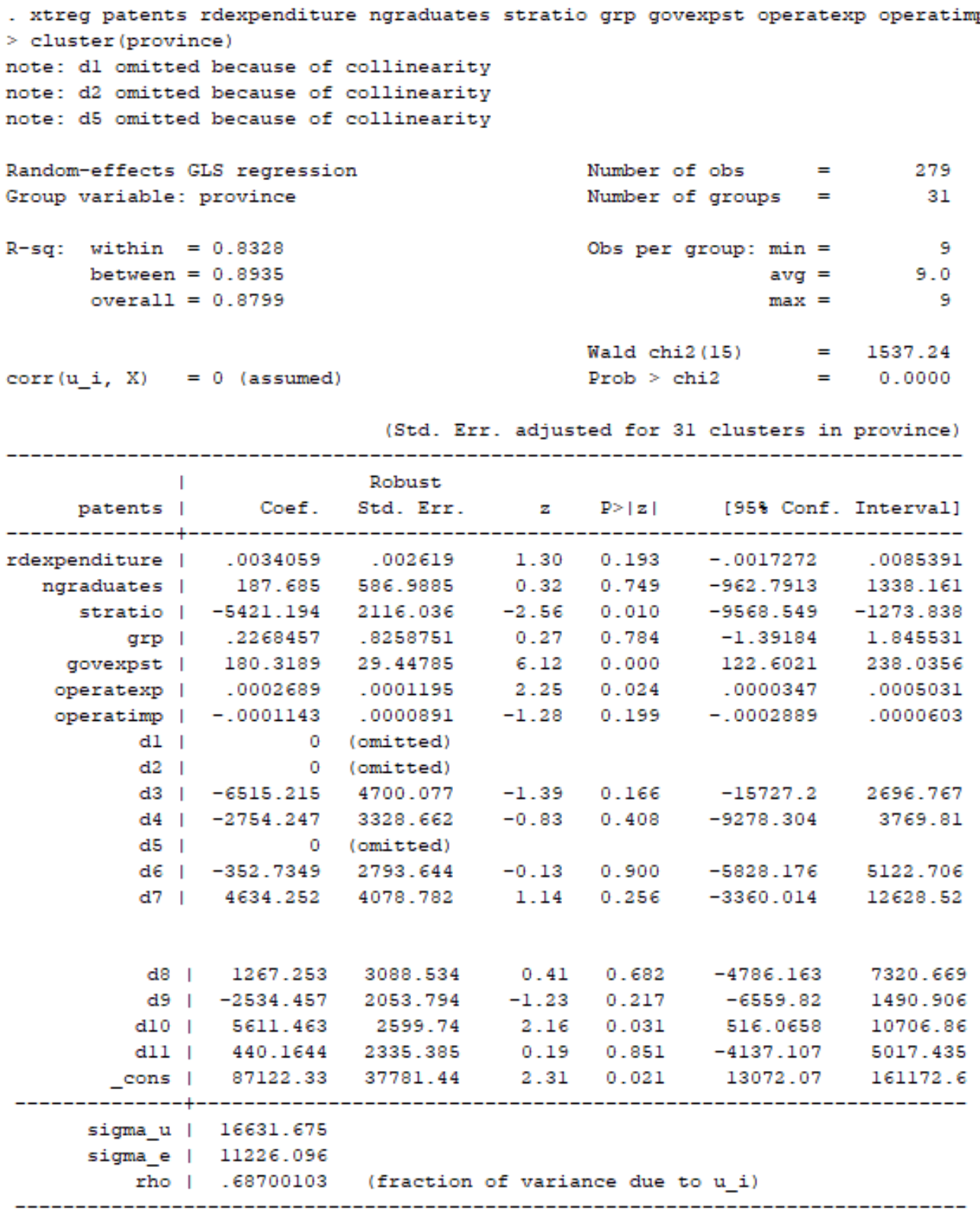

